\title{
Making Space for Permanent Molars in Growing Baboon (Papio anubis) and Great Ape (Pan paniscus and P. troglodytes) Mandibles: Possible Ontogenetic Strategies and Solutions
}

\author{
Julia C. Boughner \\ Department of Anatomy and Cell Biology, University of Saskatchewan, Health Sciences Building B328, 107 Wiggins Road, \\ Saskatoon, SK, Canada S7K 5E5 \\ Correspondence should be addressed to Julia C. Boughner, julia.boughner@gmail.com
}

Received 15 December 2010; Accepted 2 March 2011

Academic Editor: Anne M. Burrows

Copyright () 2011 Julia C. Boughner. This is an open access article distributed under the Creative Commons Attribution License, which permits unrestricted use, distribution, and reproduction in any medium, provided the original work is properly cited.

While mandible proportions do not appear to constrain permanent molar initiation times, how adequate space is created in the corpus for these teeth in a timely way is not well understood. This question is important for explaining how primate tooth and jaw development and evolution are coordinated. Landmark and linear measurement data were used to characterize mandible shape, growth trajectory, and growth rate between two genera, Papio and Pan, with contrasting permanent molar initiation schedules and mandible proportions. 3D geometric morphometric and 2D bivariate analyses showed genus-level differences in mandible morphology from birth that were amplified by different postnatal growth trajectories. Different corpus proportions and regional variation in corpus growth rates helped create space in a timely way for the molars. Regional corpus growth rates may evolve alongside permanent molar morphology and developmental timing to modify space available in the corpus for these teeth.

\section{Introduction}

Primate mandible morphologies and times of permanent molar initiation, used here to define the start of odontogenesis, vary widely across taxa. How sufficient space is created for the developing permanent molars in a growing mandible of a particular morphology at appropriate times is not well understood. Once emerged, the deciduous dentition maintains a large proportion of the space in the mandible corpus required for the permanent antemolar teeth. But for the permanent molars, space must be created anew via the growth of the jawbone. The timing of permanent molar initiation as well as molar mineralization rates and periods varies, often markedly, among primates [1-8]. Times of permanent molar initiation are not likely to be constrained by a lack of space for these teeth in the growing jaw [9]. Other work also suggests ontogenetic if not evolutionary autonomy between the teeth and the mandible [10-17], where teeth experience stronger selection pressures than do the jaws and face [17-19]. At least in African apes, the growth of toothbearing regions of the mandible is less plastic than that of edentulous regions of the jaw, notably areas of muscle attachment [20]. There is also evidence based on African ape data of developmental decoupling among various regions of the mandible corpus, ramus, condyle, and alveolar versus cortical bone that appears to be a response to the different functions of these skeletal tissues [20]. Specifically, the presence and development of the dentition may influence mandible corpus form and growth [21-24]. For example, the timing of permanent tooth initiation, emergence, and eruption may drive rates of corpus growth [21]. Regardless of whether or not the teeth directly impact mandible growth, how space is made in the mandible in a timely way for the permanent molars of species with different jaw proportions and tooth initiation schedules is a problem that is not well understood and warrants study.

The current work builds on a previous geometric morphometric test of whether space in the mandible constrained times of permanent molar initiation using Papio anubis, Pan troglodytes, and Pan paniscus as models [9]. Using 3D molar crypt and crown landmark and measurement data, this study found no significant difference in the space available 
for successive permanent molars among these three species, suggesting that mandible proportions do not constrain molar initiation times [9]. How the olive baboon and African ape mandibles grow to accommodate, respectively, more or less staggered times of permanent molar initiation needs investigating to better understand the mechanisms that coordinate primate tooth and jaw growth and evolution.

Using mandible 3D landmark data alongside 2D mandible linear measurement data, this study examines the ontogenetic changes in the proximal part of the corpus in which the permanent molar teeth form. Average mandible length is greater in adult baboons (Papio anubis) compared to adult chimpanzees (Pan troglodytes) and bonobos (Pan paniscus). Relative to the apes, baboons have not only more prognathic jaws but also anteroposteriorly longer permanent molar crowns. The initiation of successive permanent molars is more staggered over time in Papio than in Pan. However, total duration of permanent molar crown mineralization and, indeed, overall somatic maturation is shorter in Papio compared to Pan by at least three years $[25,26]$. Hence, relative to Pan, mandible growth in Papio is probably accelerated in order to achieve adult proportions that accommodate earlier forming and, in some cases, anteroposteriorly longer permanent molars. First, this study uses geometric morphometrics to compare mandible shapes and growth trajectories between Papio and Pan. Second, this work contrasts linear dimensions and growth rates of Pan and Papio mandible corpora in order to characterize how space is created in the jawbone for the permanent molars.

\section{Materials}

Papio and Pan are apt models for this study because they have contrasting mandible shapes, permanent molar initiation times, and molar mineralization periods. In the longer baboon mandible, the initiation times of successive permanent molars are more staggered; each molar crown is almost completely mineralized before the next molar begins to develop. In the shorter ape mandibles, the initiation of successive permanent molars is more rapid; molars begin to form in quicker succession with greater overlap in time. Thus Papio would appear to be a good model of a molar initiation pattern for a jaw with little to no "extra" space in it. Conversely, with more than one molar crown mineralizing at a time, Pan would appear to be a good model of a molar initiation pattern for a jaw with "extra" space in it. Ontogenetic change in mandible shape and size was studied in 52 baboons (Papio anubis), 59 chimpanzees (Pan troglodytes), and 44 bonobos (Pan paniscus). The olive baboon skulls were housed in the Natural History Museum (NHM) and the Royal College of Surgeons (RCS), both in London, UK. The chimpanzee material was housed at the NHM and the Powell-Cotton Museum (PCM), Kent, UK. The bonobo collection was housed in the Royal Museum of Central Africa (RMCA), Tervuren, Belgium. All three species were sampled across as broad and as comprehensive range of developmental ages as possible while balancing the numbers of each sex per species (Table 1).
Four age groups were defined (Table 2) within this developmental continuum, the ranges of which are explained in the next section. Briefly, age group included individuals of known (male, M; female, F) and unknown (U) sex: Papio anubis, $M=25, F=23$, and $U=3$; Pan paniscus, $M=22$, $F=17$, and $U=5 ;$. troglodytes, $M=25, F=22$, and $U=12$. These wild-shot animals were sexed using teeth, external genitalia, and nipples, and in a few cases, other external evidence $[27,28]$. All specimens were pathologyfree.

\section{Methods}

Bonobo (Pan paniscus, $n=44$ ), chimpanzee (Pan troglodytes, $n=60$ ), and olive baboon (Papio anubis, $n=60$ ) mandibles were radiographed and assigned an approximate relative dental age (ARDA) from their dental development (detailed in $[9,29]$ ). Age ranges corresponded to equivalent stages of ontogenetic growth and sexual maturity between Papio and Pan. Specimens were then assigned to one of four age groups: infants, younger and older juveniles, and adults based on their ARDA (Table 2).

Both the NHM and RCS specimens were radiographed with a Phillips Industrial Unit. A portable Faxitron Radiographic System (model 8040-310, Field Emission Limited) was used to radiograph specimens from the RCS and RMCA. Lateral and occlusal views of each mandible (Figures 1(a) and 1(c)) were taken with Kodak Industrex X-Ray Film AA4005. Lingual intraoral views of the molars (Figure 1(b)) were taken with Kodak Ultra-Speed Dental Film DF-50 Size 4.

Surface landmark data were collected from each mandible using a MicroScribe 3DX (Immersion Corp). All raw landmark coordinates were logged directly into a Microsoft Excel spreadsheet via InScribe software (Immersion Corp). Thirty-seven 3D mandible landmarks were created on the strengths of their homologies between species [30-32] and by how appropriately they visually represented overall mandible morphology and ontogenetic change in morphology (Table 3, Figure 2). Landmark data were analyzed using software program morphologika [33]. Differences of size, translation, and rotation were eliminated using Generalised Procrustes Analysis (GPA) [34-36] before executing a Principal Components Analysis (PCA) on the data to describe the principal vectors of shape variance between Papio and Pan. A GPA was chosen for the ability to visualize ontogenetic shape change and analyze variance using PCA, particularly as mandible and molar landmarks were created to describe morphological change among taxa and across growth. Shape variance was rendered visually in $3 \mathrm{D}$, first using only landmarks, and second using a constructed "wireframe" that linked adjacent landmarks according to user specifications. These vectors, or principal components (PCs), were used to explore the relationship between shape and other factors such as centroid size, the square root of the sum of squared distances of a set of landmarks from their centroid. Calculated during GPA, centroid size is equally uncorrelated with all landmarks in a given data set and thus is an unbiased measure of size for an object defined by multiple 3D landmarks. 
TABLE 1: Age groups and sexes of the specimens belonging to the three primate taxa included in this study. I: infant; J1: juvenile 1; J2: juvenile 2; A: adult.

\begin{tabular}{|c|c|c|c|c|c|c|c|c|c|c|c|c|}
\hline \multirow{2}{*}{$\begin{array}{l}\text { Taxon } \\
\text { Age group }\end{array}$} & \multicolumn{4}{|c|}{ Papio anubis } & \multicolumn{4}{|c|}{ Pan paniscus } & \multicolumn{4}{|c|}{ Pan troglodytes } \\
\hline & $\mathrm{I}$ & $\mathrm{J} 1$ & $\mathrm{~J} 2$ & $\mathrm{~A}$ & $\mathrm{I}$ & $\mathrm{J} 1$ & $\mathrm{~J} 2$ & A & $\mathrm{I}$ & $\mathrm{J} 1$ & $\mathrm{~J} 2$ & A \\
\hline \multicolumn{13}{|l|}{ Sex } \\
\hline Male & 3 & 6 & 10 & 6 & 7 & 8 & 6 & 1 & 6 & 12 & 3 & 4 \\
\hline Female & 3 & 7 & 4 & 9 & 5 & 4 & 4 & 4 & 9 & 6 & 3 & 4 \\
\hline Unknown & 1 & 1 & 1 & 0 & 3 & 1 & 1 & 0 & 7 & 5 & 0 & 0 \\
\hline Total & 7 & 14 & 15 & 15 & 15 & 13 & 11 & 5 & 22 & 23 & 6 & 8 \\
\hline
\end{tabular}

TAble 2: Age groups based on dental development for Papio and Pan.

\begin{tabular}{lcccc}
\hline & & \multicolumn{3}{c}{ Age groups (in years) } \\
Taxon & Infant & Juvenile 1 & Juvenile 2 & Adult \\
\hline Papio & $0-2.0$ & $2.01-4.5$ & $4.51-7.0$ & +7.0 \\
Pan & $0-3.5$ & $3.51-7.0$ & $7.01-10.5$ & +10.5 \\
\hline
\end{tabular}

TABLE 3: Mandible landmarks.

\begin{tabular}{|c|c|}
\hline $\begin{array}{l}\text { Number: } \\
\text { right, left }\end{array}$ & Description \\
\hline 1,21 & Superolateral-most tip of the coronoid process \\
\hline 2,22 & Inferior-most point of the mandible notch \\
\hline 3,23 & Anterior-most tip of the condyle \\
\hline 4,24 & Lateral-most tip of the condyle \\
\hline 5,25 & Posterior-most tip of the condyle \\
\hline 6,26 & Medial-most tip of the condyle \\
\hline 7,27 & Superior-most tip on the articular surface of the condyle \\
\hline 8,28 & Deepest concavity of the posterior border of the ascending ramus \\
\hline 9,29 & Point opposite landmark $8 / 28$, on the anterior border of the ascending ramus \\
\hline 10,30 & Apex of lingula, or, if lingula is undefinable or absent, the anterosuperior-most margin of the mandible foramen \\
\hline 11,31 & $\begin{array}{l}\text { Point on the posterior border of the ramus just superior to the blending of the ramus into the gonial angle or the } \\
\text { point at which a tangent leaves the posterior border of the ramus }\end{array}$ \\
\hline 12,32 & Posteriorly, the point on the gonial angle that is the apex of the $\left(90^{\circ}\right)$ angle formed by landmarks $11 / 31$ and $13 / 33$ \\
\hline 13,33 & Inferiorly, the point along the gonial angle where a tangent leaves the inferior margin of the mandible \\
\hline 14,34 & Superiorly directed indentation of the inferior border of the mandible corpus, just anterior to landmark $13 / 33$ \\
\hline 15,35 & Point at which the ascending ramus meets and obscures the corpus, in lateral view along the alveolar bone \\
\hline 16,36 & Mental foramen, midpoint at the level of the surface of the mandible corpus \\
\hline 17,37 & Point on the alveolar border of the mandible corpus directly superior to landmark 16/36 \\
\hline 18 & Midpoint between the central incisors at the superior-most tip of the alveolar bone \\
\hline 19 & Anterior-most projection of the subalveolar bone in the mental region along the midline \\
\hline 20 & $\begin{array}{l}\text { Symphyseal midpoint of the inferior margin of the mandible corpus, directly inferior to the areas of attachment of } \\
\text { the geniohyoid and genioglossus muscles }\end{array}$ \\
\hline
\end{tabular}

TABLE 4: Specimens per taxon included in the multivariate and bivariate analyses.

\begin{tabular}{lccc}
\hline Analysis & & Number of individuals per taxon included \\
Pan troglodytes & 59 & 44 \\
\hline Aging (ARDA) & 52 & 56 & 44 \\
3D Multivariate mandible shape & 50 & 58 & 44 \\
3D Multivariate mandible shape change & 52 & 21 & 28 \\
2D Bivariate mandible dimensions & 27 & & Paniscus \\
\hline
\end{tabular}




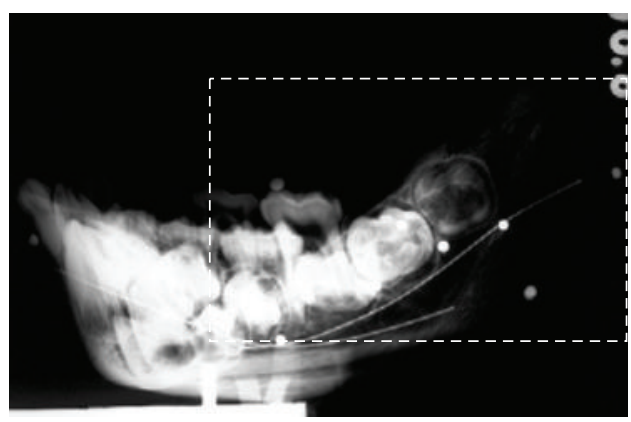

(a)

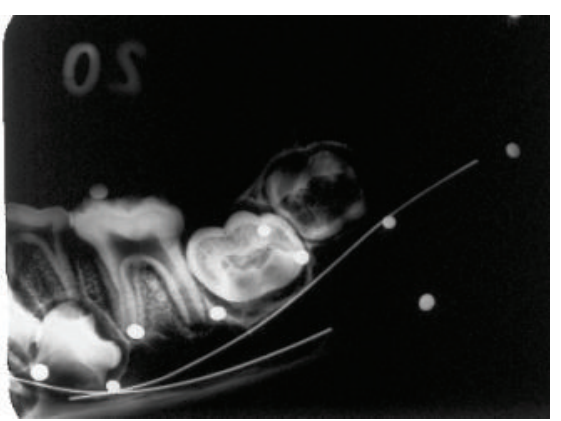

(b)

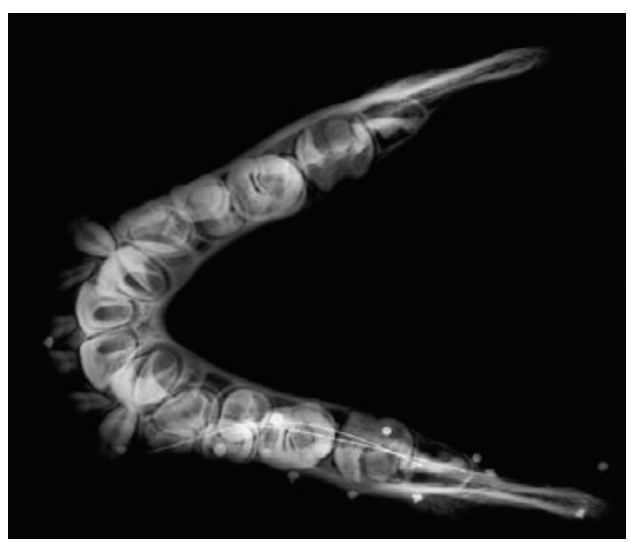

(c)

FIgURE 1: Example of radiographic image data used to determine approximate relative dental age (ARDA): Pan troglodytes mandible in lateral (a), intraoral (b) and dashed box in panel (a), and occlusal views.

Table 5: Mandible measurements.

\begin{tabular}{|c|c|}
\hline Measurement (abbreviation) & Description \\
\hline Body width (BODTH) & $\begin{array}{l}\text { The minimum thickness of the corpus measured across } \mathrm{M}_{1} \text { or the gubernaculum of the same } \\
\text { tooth with the jaws of the callipers orthogonal to the occlusal plane }\end{array}$ \\
\hline Body height $(\mathrm{BODH})$ & $\begin{array}{l}\text { Corpus height from the inferior-most point of the crest of the buccal alveolar bone opposite the } \\
\text { mesiobuccal root of } \mathrm{M}_{1} \text {, or the inferior border of } \mathrm{M}_{1} \text { gubernaculum to the lower border of the } \\
\text { mandible }\end{array}$ \\
\hline Mandible length (MANDL) & $\begin{array}{l}\text { The minimum anteroposterior length of the mandible measured between a line perpendicular to } \\
\text { the posterior-most points of the condyles to a line perpendicular to the anterior-most point of the } \\
\text { symphysis (measured with a mandible board) }\end{array}$ \\
\hline Posterior length (POSTL) & $\begin{array}{l}\text { The length of the mandible from the anterior inferior margin of the mandible foramen to the } \\
\text { distal margin of } \mathrm{dm}_{2} \text { (infant or juvenile) or from the same margin to the anterior margin of } \mathrm{M}_{1} \\
\text { (once } \mathrm{dm}_{2} \text { is shed) measured on the lingual side }\end{array}$ \\
\hline Junction width (JNCW) & $\begin{array}{l}\text { The maximum width of the corpus at the junction of the ramus and the corpus with the caliper } \\
\text { jaw orthogonal to the occlusal plane }\end{array}$ \\
\hline Ramus width (RAMAP) & The minimum anteroposterior width of the ascending ramus \\
\hline
\end{tabular}

Principal components analyses were run on a single set of all ape and baboon landmark data to compare mandible development, and on separate sets of landmark data for each species. Permutation tests determined if mandible ontogenetic trajectories were statistically different between genera. Using the PC scores from a PCA, the software program Perm PCA [37] reiteratively tested the statistical significance of the angle between species vectors of shape change across a given PC (significance $=0.05$ ). For this test, a PCA of the GPA data was run for all selected landmarks for two groups. The angle of Group 1 and then of Group 2 to the selected PC were extracted. The angle between these two angles was then computed. Next, individuals were randomly reassigned to either Group 1 or Group 2, with the same number of individuals assigned to each new group as the original groups. Finally, the angle between these groups was 
TABle 6: Raw mandible measurement data for Papio anubis. I: infant; J1: juvenile 1; J2: juvenile 2.

\begin{tabular}{|c|c|c|c|c|c|c|c|c|}
\hline \multirow{2}{*}{ Specimen ID } & \multirow{2}{*}{ ARDA (years) } & \multirow{2}{*}{ Age group } & \multicolumn{6}{|c|}{ Mandible measurements $(\mathrm{cm})$} \\
\hline & & & BODTH & $\mathrm{BODH}$ & RAMAP & MANDL & POSTL & JNCW \\
\hline $1953.655 / 32$ & 1.2 & I & 0.98 & 1.20 & 1.62 & 5.60 & 1.43 & 1.04 \\
\hline $92.21 / 76$ & 1.5 & I & 1.10 & 1.34 & 2.17 & 6.00 & 2.14 & 1.00 \\
\hline $92.182 / 75$ & 1.3 & I & 0.97 & 1.34 & 2.06 & 5.80 & 1.78 & 0.81 \\
\hline $92.22 / 79$ & 1.9 & I & 1.06 & 1.44 & 2.12 & 6.70 & 1.35 & 1.11 \\
\hline 1930.3.4.1/57 & 2.7 & $\mathrm{~J} 1$ & 1.06 & 1.71 & 2.48 & 7.80 & 3.22 & 1.16 \\
\hline 1937.7.24.1/59 & 2.8 & $\mathrm{~J} 1$ & 1.24 & 1.87 & 2.63 & 8.40 & 3.50 & 1.35 \\
\hline 1914.3.8.1/42 & 3.1 & $\mathrm{~J} 1$ & 1.10 & 1.85 & 2.60 & 8.70 & 3.56 & 1.18 \\
\hline $1967.1152 / 40$ & 3.1 & $\mathrm{~J} 1$ & 1.09 & 1.84 & 2.44 & 7.90 & 3.47 & 1.18 \\
\hline $92.3 / 74$ & 2.9 & $\mathrm{~J} 1$ & 1.09 & 2.00 & 2.78 & 8.30 & 3.52 & 1.21 \\
\hline $92.31 / 81$ & 3.9 & $\mathrm{~J} 1$ & 1.07 & 2.05 & 2.81 & 8.40 & 3.68 & 1.07 \\
\hline $92.14 / 80$ & 3.8 & $\mathrm{~J} 1$ & 1.15 & 1.78 & 2.46 & 8.00 & 2.47 & 0.70 \\
\hline $1939.1034 / 51$ & 4.4 & $\mathrm{~J} 1$ & 1.18 & 2.40 & 3.20 & 10.10 & 4.20 & 1.15 \\
\hline $1855.12 .26 .32 / 45$ & 4.4 & $\mathrm{~J} 1$ & 1.12 & 2.10 & 2.94 & 10.30 & 4.07 & 1.33 \\
\hline 1931.4.1.2/64 & 4.4 & $\mathrm{~J} 1$ & 1.16 & 2.30 & 3.31 & 9.80 & 4.23 & 1.30 \\
\hline $92.141 / 72$ & 4.4 & $\mathrm{~J} 1$ & 1.09 & 2.28 & 2.96 & 9.00 & 4.01 & 1.17 \\
\hline $1967.1151 / 41$ & 4.3 & $\mathrm{~J} 1$ & 0.98 & 1.70 & 2.52 & 8.10 & 3.36 & 1.03 \\
\hline $92.24 / 77$ & 4.4 & $\mathrm{~J} 1$ & 1.03 & 1.67 & 2.63 & 7.90 & 3.25 & 1.20 \\
\hline $92.23 / 73$ & 4.5 & $\mathrm{~J} 1$ & 1.05 & 1.86 & 2.51 & 8.00 & 2.57 & 1.10 \\
\hline $92.15 / 71$ & 5.0 & $\mathrm{~J} 2$ & 1.15 & 2.14 & 3.10 & 9.20 & 4.27 & 1.14 \\
\hline $1913.10 .18 .1 / 47$ & 5.3 & $\mathrm{~J} 2$ & 1.08 & 2.52 & 3.35 & 10.20 & 4.90 & 1.23 \\
\hline $92.36 / 78$ & 5.0 & $\mathrm{~J} 2$ & 1.08 & 2.23 & 3.02 & 9.80 & 4.49 & 1.21 \\
\hline $92.12 / 70$ & 5.3 & $\mathrm{~J} 2$ & 1.12 & 2.75 & 3.40 & 10.60 & 5.06 & 1.42 \\
\hline $1924.8 .6 .14 / 43$ & 5.3 & $\mathrm{~J} 2$ & 1.22 & 2.23 & 3.11 & 9.80 & 4.17 & 1.39 \\
\hline $1939.55 / 44$ & 5.3 & $\mathrm{~J} 2$ & 1.22 & 2.20 & 3.40 & 9.70 & 4.43 & 1.36 \\
\hline $1928.6 .3 .1 / 35$ & 5.3 & $\mathrm{~J} 2$ & 1.11 & 2.34 & 3.43 & 10.30 & 4.91 & 1.43 \\
\hline $1939.3451 / 67$ & 5.7 & $\mathrm{~J} 2$ & 1.22 & 3.09 & 3.66 & 12.50 & 5.33 & 1.36 \\
\hline $1973.18 .12 / 65$ & 5.9 & $\mathrm{~J} 2$ & 1.14 & 2.78 & 3.57 & 12.10 & 5.67 & 1.35 \\
\hline
\end{tabular}

recomputed. All this was done for one thousand iterations. The number of times that the permuted angles were smaller than the initially computed true angle yielded the $P$ value.

To determine if mandible shape differed significantly between species throughout ontogeny, the mean shape of the GPA-registered landmark data was calculated for each of the four age groups in both genera and run through permutations tests of difference of means $(P=.5)$. This was a direct and assumption-free test of the significance of differences between infant, younger and older juvenile, and adult mean jaw shapes.

To reintroduce absolute size data and compare actual change in ramus and corpus lengths and widths with age, linear measurements were made on the same mandibles that had been digitized and radiographed. Time constraints on data collection limited the number of specimens that could be radiographed and landmarked as well as measured. Subsequently, sample sizes varied with the type of analysis (Table 4).

The mental and mandible foramina were used to subdivide the corpus into proximal and distal parts in order to more precisely study growth rates, particularly in the area of the corpus that housed the permanent molars. The foramina were chosen because they are homologous structures that are immediately recognizable and remain relatively static during growth. Further, the decision to subdivide the mandible near M1 or the mental foramen was informed by other studies showing functional and/or developmental modularity of the lower jaw at this point along the corpus [20, 38-41]. Five measurements (Table 5, Figure 3) were taken from the right side of each mandible unless it was damaged, in which case the left side was used. Measurements were made using manual callipers and an osteometric board and were rounded to the hundredth decimal place. Measurement data were analysed with Microsoft Excel (MS Windows 2003) and SPSS software (IBM version 19).

Tests of linearity (means comparison, ANOVA SPSS v.19) confirmed that the scatters of the bivariate plots of mandible dimensions against age (ARDA) and other jaw measurements were linear, enabling the comparison of slopes and absolute growth rates of the corpus. Also, plots of residuals showed random distributions around zero as would be expected for linear trends. Further, linear regression analysis showed strong goodness of fit for the bivariate plots. Where the data conform less tightly to a linear distribution is for older juveniles of all three species. This may be 
TABLE 7: Raw mandible measurement data for pan trolodytes. I: infant; J1: juvenile 1; J2: juvenile 2.

\begin{tabular}{|c|c|c|c|c|c|c|c|c|}
\hline \multirow{2}{*}{ Specimen ID } & \multirow{2}{*}{ ARDA (years) } & \multirow{2}{*}{ Age groups } & \multicolumn{6}{|c|}{ Mandible measurements $(\mathrm{cm})$} \\
\hline & & & BODTH & $\mathrm{BODH}$ & RAMAP & MANDL & POSTL & JNCW \\
\hline $1939.1000 / 15$ & 2.7 & $\bar{I}$ & 1.04 & 1.44 & 2.17 & 6.30 & 1.38 & 0.95 \\
\hline $1948.439 / 9$ & 2.7 & $\mathrm{I}$ & 1.13 & 1.31 & 1.97 & 6.50 & 1.86 & 1.06 \\
\hline $1939.1004 / 17$ & 2.7 & I & 1.22 & 1.40 & 2.10 & 7.30 & 2.00 & 1.18 \\
\hline $1986.221 / 6$ & 2.7 & I & 1.05 & 1.14 & 2.09 & 6.10 & 1.80 & 1.10 \\
\hline $1948.438 / 11$ & 2.7 & I & 0.96 & 1.31 & 2.29 & 6.60 & 1.85 & 1.16 \\
\hline $1986.217 / 100$ & 2.7 & I & 1.24 & 1.39 & 2.18 & 6.50 & 1.71 & 1.17 \\
\hline $1939.915[\mathrm{~b}] / 10$ & 3 & I & 1.06 & 1.21 & 2.04 & 6.20 & 1.84 & 1.01 \\
\hline $1939.979 / 8$ & 3 & I & 1.22 & 1.47 & 2.24 & 7.50 & 2.06 & 1.06 \\
\hline $1939.997 / 18$ & 3.2 & I & 1.20 & 1.75 & 2.82 & 7.40 & 2.30 & 1.20 \\
\hline $1980.341 / 5$ & 3 & I & 1.24 & 1.52 & 2.31 & 7.20 & 2.25 & 1.16 \\
\hline $1939.1003 / 16$ & 3.2 & I & 1.12 & 1.65 & 2.51 & 7.35 & 2.00 & 1.20 \\
\hline $1939.3373 / 19$ & 3.4 & I & 1.43 & 1.69 & 2.73 & 8.60 & 3.26 & 1.45 \\
\hline $1846.10 .23 .11 / 7$ & 3.8 & $\mathrm{~J} 1$ & 1.23 & 1.57 & 2.87 & 8.70 & 3.32 & 1.29 \\
\hline $1939.1002 / 4$ & 4.5 & $\mathrm{~J} 1$ & 1.20 & 1.79 & 2.87 & 8.20 & 2.93 & 1.15 \\
\hline $1980.339 / 3$ & 4.6 & $\mathrm{~J} 1$ & 1.24 & 1.71 & 2.60 & 9.21 & 3.20 & 1.08 \\
\hline $1939.998 / 20$ & 4.5 & $\mathrm{~J} 1$ & 1.37 & 1.94 & 2.98 & 8.90 & 3.45 & 1.38 \\
\hline 1926.11.18.1/24 & 6 & $\mathrm{~J} 1$ & 1.26 & 2.08 & 3.27 & 10.38 & 3.90 & 1.39 \\
\hline 1901.8.9.9/25 & 6 & $\mathrm{~J} 1$ & 1.31 & 1.94 & 3.04 & 11.00 & 3.58 & 1.47 \\
\hline $1887.12 .1 .3 / 12$ & 7.4 & $\mathrm{~J} 2$ & 1.25 & 2.27 & 3.59 & 10.90 & 4.34 & 1.71 \\
\hline $1989.326 / 27$ & 7 & $\mathrm{~J} 1$ & 1.20 & 2.52 & 3.48 & 11.77 & 4.57 & 1.55 \\
\hline $1989.327 / 23$ & 5 & $\mathrm{~J} 1$ & 1.23 & 1.85 & 3.07 & 8.50 & 3.34 & 1.33 \\
\hline
\end{tabular}

because stages of tooth mineralization and eruption are most varied and variable during this time period, and thus age estimates are more error prone. To pre-empt skewing due to the age distribution of each data set [42], individuals with no less than fully emerged deciduous dentitions or no more than completely mineralized $\mathrm{M}_{3}$ crowns were included (Table 4). An ANCOVA is statistically determined within a 95\% confidence interval if growth rates (slopes of age plotted against a given jaw measurement) differed significantly among taxa.

\section{Results}

4.1. From Infancy, Papio and Pan Mandible Shapes and Ontogenetic Trajectories Differ Statistically in Mean Mandible Shape. After a PCA of all mandible landmarks, permutations tests showed that mean mandible shapes were significantly different between Papio and Pan from infancy through to adulthood $(P<.001$ for all four age groups). Across principal components (PCs) 1-4, shape variance was not associated with sexual dimorphism in any age group for either genus. Shape differences between genera described by PC5 and higher were very subtle and thus are not reported here. Between Papio and Pan, the same six major differences in mean mandible shape were noted in each of the four age groups (Figures 4(a) and 4(b)). Note that because absolute specimen size was removed by GPA, the following references to length, height, and width are only relative.

First, as described by PC1, proximal and distal parts of the corpus contributed differently to total corpus length.
In Papio, a subsection of the corpus (proximal corpus) defined from the mental foramen proximal (backward) to the anterior edge of the ascending ramus was longer than the length of the corpus (distal corpus) distal to (in front of) the mental foramen. The opposite was seen in Pan, where the distal corpus was longer relative to the proximal corpus. Related to this, the mental foramen shifted distally with increasing age in Papio but was largely static in Pan. Second, described by PC2, the mandible condyle was taller than the coronoid process in Pan, while the inverse was seen in Papio. Also, the buccal face of the corpus was concave in Papio but relatively flat in Pan. Fourth, anteroposterior (AP) ramus width was smaller relative to corpus length in Papio compared to Pan. This difference between genera increased with age. Fifth, across PC3, the surface area of the gonial angle was larger in Papio than Pan. Finally, PC4 described a slightly more acute gonial angle in $\mathrm{Pan}$, although the gonial angles of both genera exceeded $90^{\circ}$ in infants to adults.

4.2. Mandible Shape Trajectory. Across PC1, individuals were distributed approximately by their centroid size (Figure 5). Statistical tests confirmed that PC1 and centroid size correlated strongly in Papio (0.83) and Pan (0.90) $(P<.0001)$. Thus, PC1 described shape variance related to mandible ontogeny. Further, PC1 described $49.9 \%$ of the total variance in mandible shape between genera. Thus, half of the total shape variance in the lower jaw was directly related to its ontogenetic growth. PC2 also correlated positively with centroid size in Pan (0.87) and Papio $(0.77)(P<.0001)$, but PC2 described only $16.8 \%$ of the total shape variance. 
TABle 8: Raw mandible measurement data for Pan paniscus. I: infant; J1: juvenile 1; J2: juvenile 2.

\begin{tabular}{|c|c|c|c|c|c|c|c|c|}
\hline \multirow{2}{*}{ Specimen ID } & \multirow{2}{*}{ ARDA (years) } & \multirow{2}{*}{ Age group } & \multicolumn{6}{|c|}{ Mandible measurements $(\mathrm{cm})$} \\
\hline & & & BODTH & BODH & RAMAP & MANDL & POSTL & JNCW \\
\hline $18050 / 6$ & 3.2 & $\mathrm{I}$ & 1.00 & 1.30 & 2.04 & 5.80 & 1.70 & 1.00 \\
\hline $11293 / 8$ & 1.8 & I & 1.02 & 1.20 & 1.90 & 5.70 & 1.30 & 1.05 \\
\hline $12087 / 9$ & 3.3 & I & 1.10 & 1.50 & 2.30 & 6.40 & 2.10 & 1.13 \\
\hline $22336 / 17$ & 3.4 & $\mathrm{I}$ & 1.15 & 1.60 & 2.10 & 6.00 & 2.10 & 1.10 \\
\hline $23464 / 18$ & 3.3 & $\mathrm{I}$ & 1.10 & 1.30 & 2.20 & 6.20 & 2.10 & 1.00 \\
\hline $26959 / 25$ & 3.2 & I & 1.20 & 1.33 & 2.10 & 6.40 & 2.00 & 1.10 \\
\hline $26958 / 24$ & 3.3 & I & 1.10 & 1.40 & 2.20 & 6.10 & 1.90 & 1.14 \\
\hline $26972 / 34$ & 2.4 & I & 0.93 & 1.10 & 2.00 & 5.80 & 1.50 & 0.90 \\
\hline $26975 / 36$ & 3.5 & I & 1.20 & 1.50 & 2.44 & 7.10 & 2.40 & 1.30 \\
\hline $26976 / 37$ & 2.6 & I & 1.10 & 1.30 & 2.00 & 5.80 & 1.50 & 1.00 \\
\hline $26977 / 23$ & 3.0 & I & 1.10 & 1.40 & 2.20 & 6.30 & 1.80 & 1.00 \\
\hline $26990 / 0$ & 2.8 & I & 1.00 & 1.20 & 1.90 & 5.40 & 1.40 & 0.93 \\
\hline $11528 / 10$ & 6.0 & $\mathrm{~J} 1$ & 1.00 & 1.80 & 2.50 & 8.00 & 2.90 & 1.30 \\
\hline $9369 / 11$ & 4.9 & J1 & 1.00 & 1.50 & 2.23 & 7.00 & 1.92 & 1.10 \\
\hline $26936 / 19$ & 4.0 & $\mathrm{~J} 1$ & 1.10 & 1.40 & 2.30 & 7.20 & 2.60 & 1.10 \\
\hline $22908 / 20$ & 6.5 & J1 & 0.90 & 1.60 & 2.60 & 8.30 & 3.30 & 1.10 \\
\hline $26968 / 26$ & 3.9 & $\mathrm{~J} 1$ & 0.23 & 1.50 & 2.40 & 7.00 & 2.20 & 1.30 \\
\hline $26970 / 27$ & 4.2 & J1 & 1.10 & 1.40 & 2.60 & 7.80 & 2.80 & 1.20 \\
\hline $26982 / 33$ & 4.4 & J1 & 1.10 & 1.30 & 2.60 & 7.80 & 2.70 & 1.20 \\
\hline $26969 / 35$ & 3.9 & J1 & 1.01 & 1.40 & 2.30 & 7.40 & 2.50 & 1.10 \\
\hline $26988 / 28$ & 6.5 & J1 & 1.10 & 1.70 & 2.70 & 8.00 & 3.10 & 1.20 \\
\hline $27001 / 3$ & 6.7 & J1 & 1.10 & 1.70 & 2.90 & 8.40 & 3.50 & 1.20 \\
\hline $5374 / 13$ & 7.3 & $\mathrm{~J} 2$ & 1.16 & 1.90 & 2.80 & 9.10 & 3.20 & 1.26 \\
\hline $26947 / 29$ & 7.6 & $\mathrm{~J} 2$ & 1.10 & 1.80 & 3.10 & 9.60 & 3.70 & 1.30 \\
\hline $26971 / 32$ & 7.5 & $\mathrm{~J} 2$ & 1.20 & 1.90 & 3.40 & 9.70 & 3.80 & 1.40 \\
\hline $26994 / 4$ & 7.2 & $\mathrm{~J} 2$ & 1.20 & 1.90 & 3.20 & 9.40 & 3.60 & 1.40 \\
\hline $26993 / 5$ & 8.0 & $\mathrm{~J} 2$ & 1.10 & 1.90 & 3.40 & 9.40 & 3.50 & 1.20 \\
\hline $26996 / 2$ & 8.0 & $\mathrm{~J} 2$ & 1.10 & 2.00 & 3.50 & 9.70 & 3.60 & 1.34 \\
\hline
\end{tabular}

Subsequent PCs 3-6 described 5.12\%, 3.27\%, 2.34\%, and $2.20 \%$ of the remaining total shape variance, respectively. PCs 7 and higher each described less than $2 \%$ of the total variance. Shape change described only by PCs 1, 2, and 3 statistically distinguished Papio from Pan.

Vectors of baboon and ape mandible shape variance across PCs 1 and 2 were statistically different as confirmed by a permutation test $(P<.0009)$. Again, as absolute size was removed by a GPA prior to a PCA, changes in jaw proportion are discussed here in relative terms only. These changes are similar to what was seen in the multivariate analysis of mean mandible shape. Across PC1, the mandible lengthened visibly during development in Pan and Papio, but much more in Papio. In the baboon, the extension of the corpus proximal to the mental foramen as far back as the anterior margin of the ramus contributed to a much greater proportion of adult corpus length. In contrast, this subsection of the corpus did not elongate substantially in either the chimpanzee or the bonobo. Rather, in Pan corpus length distal to the mental foramen increased notably. The greater length of the adult baboon mandible was due to growth across the entire length of the corpus, in both the distal and proximal subsections of the jaw (Figure 5). Conversely, growth in the distal subsection of the corpus and in anteroposterior ramus width contributed more to final adult mandible length in both apes (Figures 4(a) and 5). In Pan, the proximal subsection (from the mental foramen to the ascending ramus) changed relatively little over time (Figures 4 (b) and 5).

4.3. Growth Rates Differ Regionally within the Corpus and between Papio and Pan. Statistical shape analyses showed significantly different mean mandible shapes and growth trajectories between Pan and Papio. Next, absolute linear measurements of Papio and Pan mandibles (Tables 6, 7, and 8 , Figures 6-7) were statistically compared to assess their rates of growth from infancy to adulthood.

In Papio, total mandible length (MANDL) increased about $1 \mathrm{~cm}$ for every year of postnatal growth (Figure 6(a)). By 6 years of age, MANDL had more than doubled its infant length in the baboon. By the same age, MANDL had grown only an additional $75 \%$ of infant dimensions in bonobos and only about $60 \%$ in chimpanzees. In infant apes, MANDL was about $1 \mathrm{~cm}$ greater in the chimpanzee compared to the bonobo. This size difference approximately doubled between 


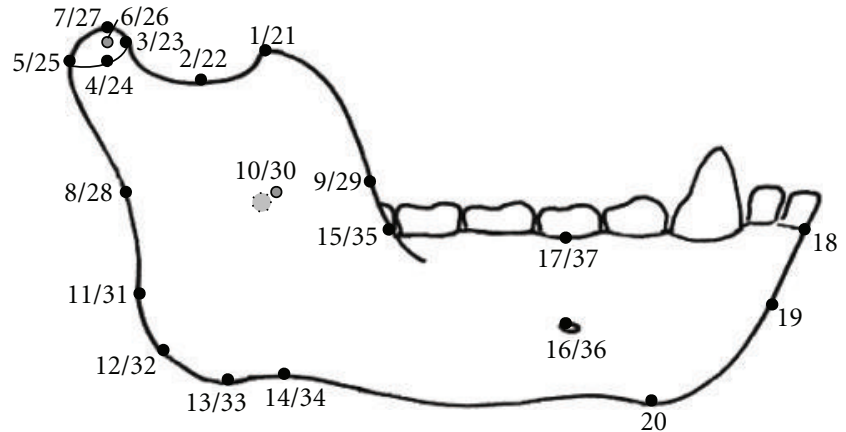

(a)

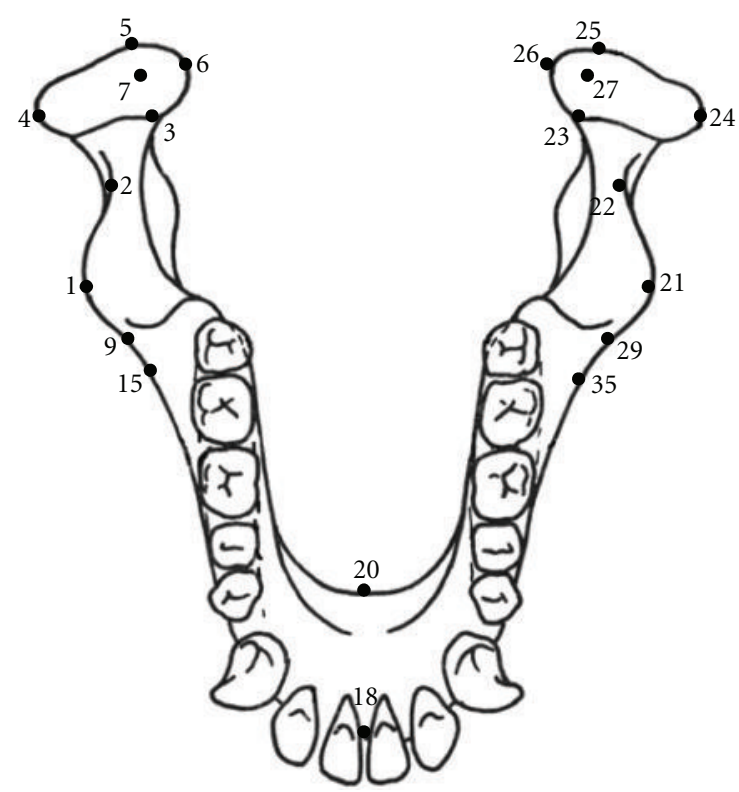

(b)

Figure 2: Mandible landmarks: (a) buccal view and (b) occlusal view.

P. paniscus and $P$. troglodytes by early adulthood. In a plot of total mandible length against age (ARDA), the slopes (rates of growth) were almost equivalent between Papio and Pan troglodytes $\left(m=1.1\right.$ for both; $R^{2}=0.80$ and 0.89 , resp.) (Figure 6(a)). MANDL grew only somewhat more slowly in the bonobo $\left(m=0.7, R^{2}=0.92\right)$. Thus, total mandible length grew at about equal rates in $P$. troglodytes and Papio and about $2 / 3$ slower in $P$. paniscus. An analysis of covariance (ANCOVA) of MANDL versus ARDA showed statistical differences among species $(F$-value $=65.2, P<$ $.001)$ and between genera $(F$-value $=25.57, P<.001)$.

Next, growth rates for the posterior length of the corpus housing the permanent molars (POSTL), measured from the anterior margin of the $\mathrm{M}_{1}$ crypt/tooth back to the mandible foramen (Figure 3), were compared. The slope of POSTL against age (ARDA) was slightly larger (thus faster growth rate) in Papio ( $m=0.7)$ compared to Pan (P. troglodytes, $m=0.6, P$. paniscus, $m=0.4$ ) (Figure 6(b)). Distributions differed significantly between Papio and Pan (ANCOVA, Fvalue $=153.35, P<.001)$ and among all three species $(F$ value $=130.8, P<.001)$. As with MANDL, correlation between POSTL and ARDA was strong for bonobos $\left(R^{2}=\right.$ $0.92)$, chimpanzees $\left(R^{2}=0.95\right)$, and baboons $\left(R^{2}=0.87\right)$. In infancy, POSTL measured about the same in the apes (less than $0.5 \mathrm{~cm}$ longer in chimpanzees versus bonobos) and was half again longer in the baboon. By adulthood, POSTL had almost quadrupled in Papio. In contrast, POSTL had, at most, tripled in Pan and was almost $1 \mathrm{~cm}$ longer in young adult chimpanzees compared to bonobos. The length of this molar-bearing region of the corpus also increased at a slightly faster rate in chimpanzees $(m=0.6)$ versus bonobos $(m=$ 0.4) (Figure 6(b)). In adult Papio, POSTL was about half again longer compared to adult Pan.

Even from infancy, the molar-bearing region of the corpus (POSTL) contributed to a greater proportion of total mandible length (MANDL) in Papio compared to Pan (Figure 6(c)). By adulthood, POSTL made up about $1 / 2$ of MANDL in Papio and just over $1 / 3$ of MANDL in Pan. POSTL correlated very strongly with MANDL in all three species (bonobo, $R^{2}=0.95$; chimpanzee, $R^{2}=0.93$; baboon, $\left.R^{2}=0.94\right)$. In both Papio and Pan, POSTL grew at about half the rate of MANDL (bonobo, $m=0.54$; chimpanzee, $m=0.52$ ); baboon, $m=0.58$ ) although growth rates of POSTL relative to MANDL were statistically different between genera (ANCOVA, $F$-value $=48.17, P<.001$ ) and among the three species $(F$-value $=45.2, P<.001)$.

As with total mandible length, corpus height measured at $\mathrm{M}_{1}$ (BODH) grew slightly but significantly faster in baboons $\left(m=0.3, R^{2}=0.74\right)$ than in chimpanzees $(m=0.2$, $\left.R^{2}=0.85\right)$ or bonobos $\left(m=0.1, R^{2}=0.86\right)$ (ANCOVA was significant for all species $F=67.5, P<.001$; genera $F=$ $45, P<.001)$. BODH was also absolutely tallest in baboons and shortest in bonobos. Across age groups, there was very little change in corpus width measured at $\mathrm{M}_{1}$ (BODTH), which increased at most $0.5 \mathrm{~cm}$ from infancy to adulthood in all three species with correlations between width and age $\left(R^{2}=0.24,0.05\right.$, and 0.27 in Papio, P. paniscus, and P. troglodytes, resp.) that were so weak as to be almost meaningless. Variation in growth rate of BODTH was statistically significant among species (ANCOVA, $F$-value $=$ 9.53, $P<.001)$ but not between genera $(F$-value $=0.26$, $P=.78)$. The width of the corpus at its junction with the ascending ramus (JNCW) is an area in which molar crypts and teeth may start to form, likely to compensate for a lack of space in the corpus proper. Rates of widening for JNCW were fastest in Pan troglodytes $(m=0.1)$ and slowest in $P$. paniscus $(m=0.05)$ (Papio $m=0.07)$. While correlation with ARDA was strong in chimpanzees $\left(R^{2}=0.78\right)$, it was moderate for bonobos and baboons $\left(R^{2}=0.55\right.$ and 0.49 , resp.). There was very little change in JNCW over time and no significant difference between Papio and Pan (ANCOVA, $F$-value $=0.61, P=.55)$ but a statistical difference among all 3 species (ANCOVA, $F$-value $=7.49, P=.001$ ).

Anteroposterior ramus width (RAMAP) increased at similar rates in baboons, chimpanzees $\left(m \approx 0.3, R^{2}=\right.$ 0.81 and 0.85 , resp. $)$, and bonobos $\left(m=0.2, R^{2}=0.87\right)$ (Figure $7(\mathrm{a})$ ). However, covariance was statistically different among all species $(F$-value $=42.5, P<.001)$ and between genera $(F$-value $=21.1, P<.001)$. For all species across all age groups, RAMAP remained very similar in proportion to 


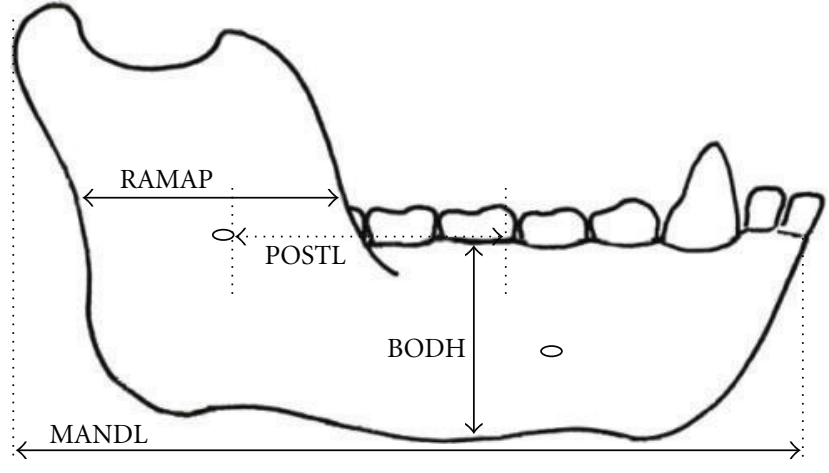

(a)

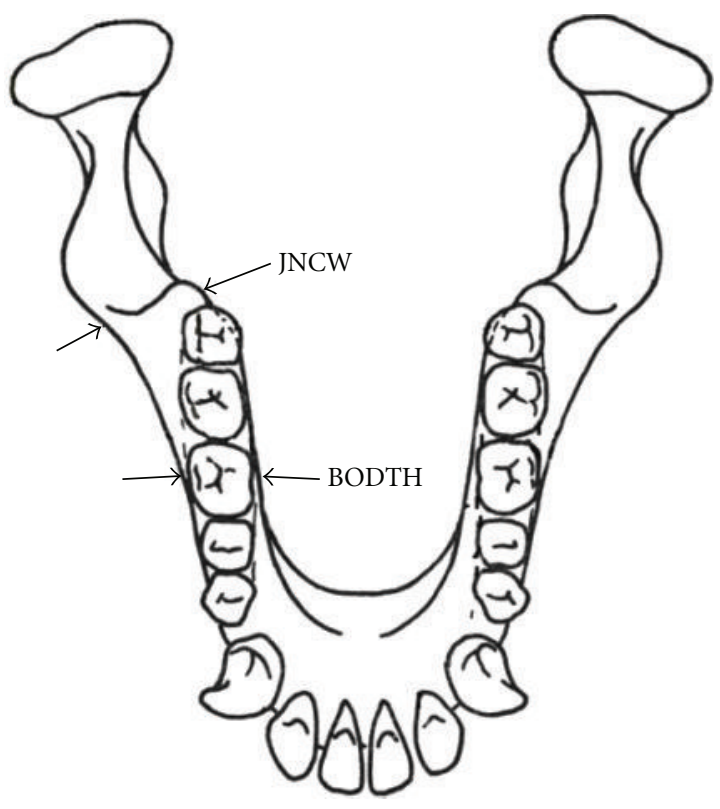

(b)

FIgure 3: Mandible linear measurements: (a) buccal view and (b) occlusal view.

total mandible length (about 1/3 of MANDL) (Figure 7(b)). Ramus width made up a slightly greater proportion of total mandible length in Pan compared to Papio. Based on the radiographic data, permanent molar crypts and teeth begin to form in not only the mandible corpus but also the anterior portion of the ascending ramus in both genera.

\section{Discussion}

Mandible shape was statistically distinct between Papio and Pan from infancy through adulthood. Thus, as might be expected, genus-level differences in mandible shape were established perinatally and probably even before birth. Mandible ontogenetic trajectory was also discrete between Papio and Pan. As such, genus-level differences in adult mandible morphology arose from a combination of differences in jaw shape near birth that were augmented and entrenched by different postnatal growth patterns. These results contrast with a recent report that while mandible shape differed between sister species Pan paniscus and $P$. troglodytes from infancy, postnatal mandible growth pattern did not [43]. Thus, while a single mandible growth pattern may be shared by species within a genus, jaw growth patterns would appear to differ between genera. Earlier work contrasting Gorilla and Pan mandible morphology and growth supports this idea [20]. While yet to be proven if mandible growth pattern is conserved within a genus, then, data allowing, it would be a useful taxonomic indicator at the genus level. Perhaps more interesting is that this finding implies a decoupling of dental development and jaw development, where dental development schedule and pattern are species specific, but jaw development pattern is not necessarily so. These findings are intriguing and more work needs to be done to both confirm them in other primate taxa and to explore the evolutionary and developmental mechanisms underlying them.

Compared to chimpanzees, baboon molars mineralize within shorter periods of time and become functional at much younger chronological ages $[4,25,26,44,45]$. The baboon's permanent molars are also longer anteroposteriorly than those of the apes. For this reason, rates of lower jaw growth were expected to be accelerated in Papio in order to accommodate earlier molar development and emergence. This expectation was confirmed here by faster growth in corpus length and height and, to a degree, ramus width, in Papio compared to Pan. Specifically, the length of the corpus housing the permanent molars (POSTL) contributed to a greater proportion of total jaw length (MANDL) in Papio compared to Pan. POSTL as well as MANDL also grew at faster rates in Papio. Thus, in the baboon faster growth rates of the corpus, particularly the part of the alveolus that houses the permanent molars correlates positively with longer molar crown length and earlier timing of tooth initiation/emergence. Variation in growth rates across the length of the corpus suggests that if the permanent dentition is driving corpus growth [21], then different permanent teeth (i.e., antemolar versus molar) influence the alveolus in different ways.

From infancy to adulthood, there was very little, although still significant, change in corpus width (BODTH, taken at $\mathrm{M}_{1}$ or at the site of its dilating gubernaculum) in either genus. The width of the corpus measured at its junction with the ascending ramus (JNCW) also increased minimally with age in Papio and Pan. Thus, corpus width achieved adult size earlier in life and did not appear to contribute much new space for the permanent molars. Throughout growth 


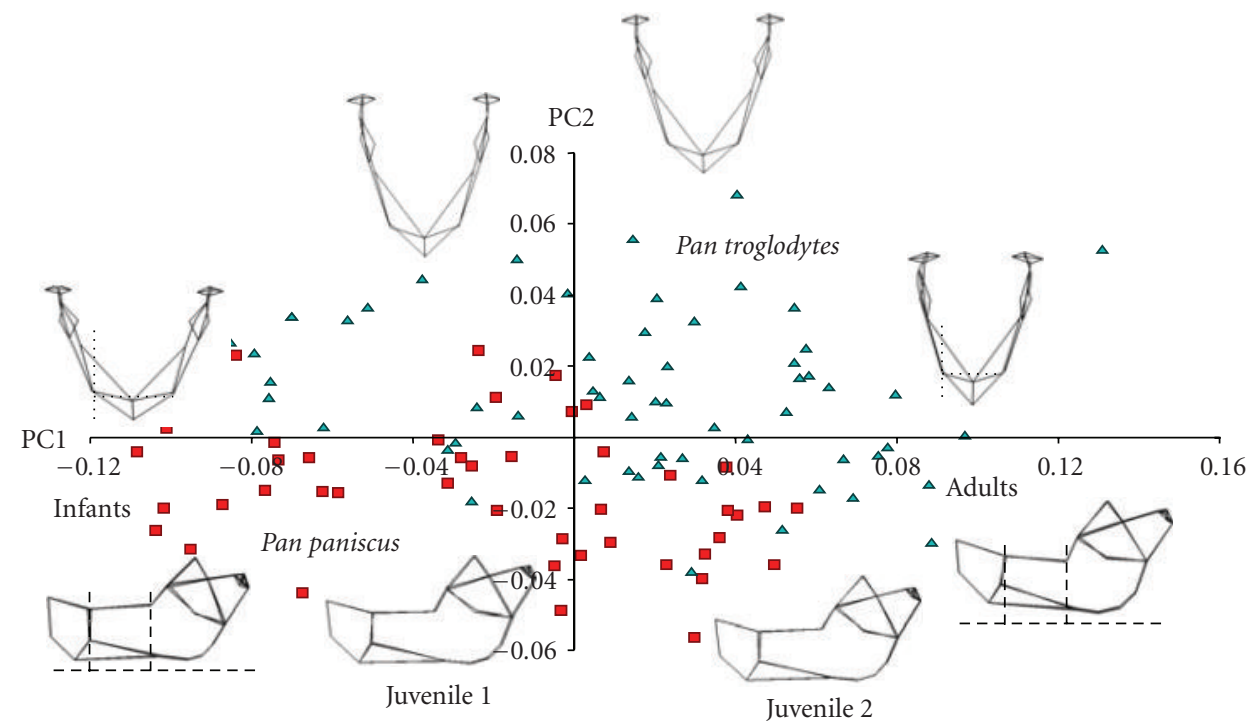

(a)

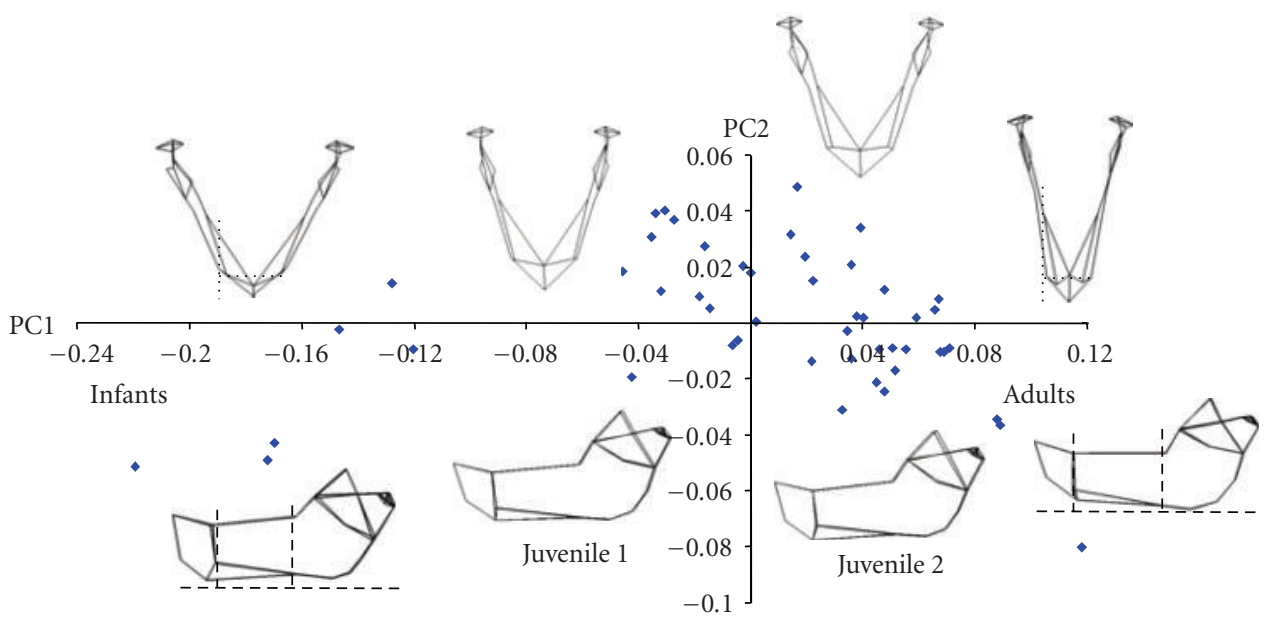

(b)

FIgURe 4: A principal components analysis of mean mandible shape in infant, juvenile, and adult Pan (a) and Papio (b) across PC1 and PC2 described significant shape differences between genera. Occlusal (upper) and buccal (lower) views of "wire frames" illustrate mean mandible shape for each of the four age groups. Infants are at left and adults are at right. Relative to corpus breadth across the mental foramina, the corpus lengthens much more in Papio than in Pan (dotted lines). Growth in anteroposterior ramus width and corpus length distal to the mental foramen contributes more to adult jaw proportions in Pan than in Papio. In Papio, corpus growth proximal to the mental foramen contributes relatively more (dashed lines). Red squares, Pan paniscus; teal triangles, Pan troglodytes; blue diamonds, Papio anubis.

and certainly by young adulthood, anteroposterior (A-P) ramus width (RAMAP) contributed to about $1 / 3$ of the total mandible length in the apes and to between $1 / 3$ and $1 / 4$ in the baboon. Based on the radiographic data, permanent molar crypts and initiating teeth formed in the anterior rami of both Pan and Papio. However, variation in A-P ramus width would seem to be much more an outcome of biomechanical demands than a response to the spatial requirements of the developing molars.

Mandible shape is in large part entrenched at a fundamental, molecular level [46-50], but adult jaw morphology arises from a complex combination of genetic, epigenetic and biomechanical inputs [51]. The functional demands of mastication and a biomechanical balance of stability, manoeuvrability, and force significantly impact mandible form [52-54]. This includes the different vectors of force exerted on the growing mandible by the developing masticatory muscles [55-59]. Broadly, taxonomic differences in gonial angle size, ramus height, and condyle position are related to the mechanical efficiency of the masticatory muscles and the maximum occlusal forces they exert [6064]. Thus, differences in gonial shape between Papio and Pan likely reflect the different positions and masses of masticatory muscles that exert different vectors of force on the bone in this gonial region and across the ramus. These effects may be conditional, perhaps on mandible proportion and size 


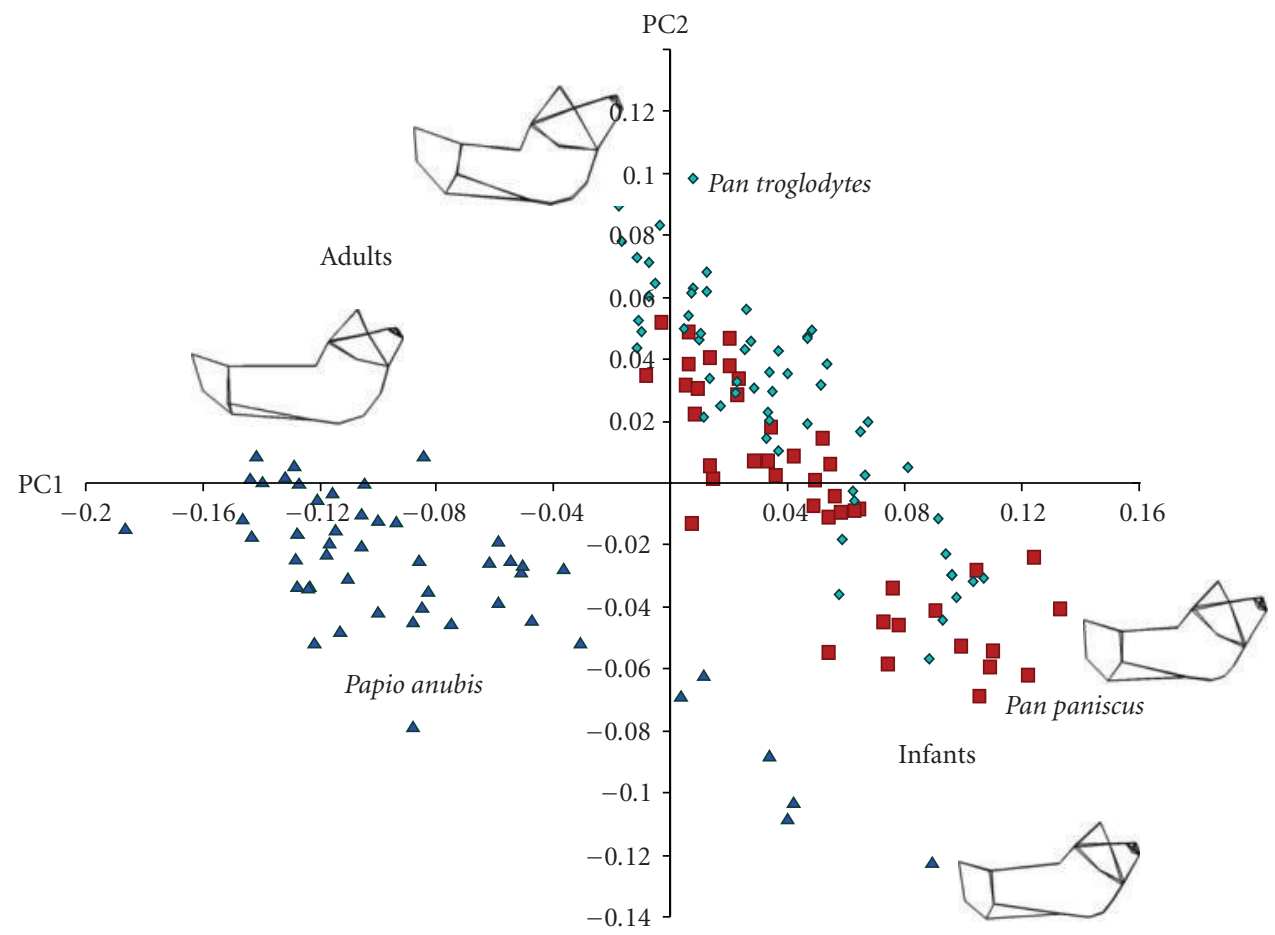

Figure 5: On the plot of mandible shape variance across PCs 1 and 2 for Papio and Pan, PC1 describes variance that is closely associated with ontogenetic growth. The scatters of Papio and Pan do not overlap; the angle between both scatters is statistically significant, indicating that the mandibles of each genus follow different ontogenetic trajectories to different adult shapes (wireframes, upper left). Both scatters are linear. Thus, mandible growth trajectory is established at or before birth. Red squares, Pan paniscus; teal diamonds, Pan troglodytes; blue triangles, Papio anubis.

$[53,60,65]$ and proportion of "slow" and "fast" muscle fibre types [57]. While diets vary compositionally between bonobos and chimpanzees, what they eat is rather the same: both species dine on large amounts of sweet arboreal fruits, followed by lesser quantities of herbs and herbivorous vegetation [66-70]. Typically, baboons predominantly consume vegetable food year round, the bulk of which is made up by grasses [71, 72]. Seasonal fruits and rhizomes make up the second largest proportion of the baboon's diet [71]. However, diet composition can vary according to grassland versus forested habitat [73]. These differences in food type and texture and diet composition inevitably translate into different strengths and forces of masticatory muscle action and varying effects on mandible form.

Finally, as is the focus of this paper, the growing mandible must accommodate the mineralizing permanent dentition and its emergence into proper functional occlusion. Tooth shape and size account for another part of the taxonomic variation in corpus length and width [60]. African ape edentulous jawbone was more plastic than was alveolar bone, and regional differences in jaw function appear to have translated into developmental decoupling (or vice versa) among these various regions such as mandible corpus, ramus, condyle, and alveolus. However, this report [20] did not mention regional differences in growth rates within the corpus alone.

There is evidence in humans of variation in postnatal growth rates across the mandible [39] and a primary growth centre near the position of $M_{1}$ [38]. A 3D study of the developing human mandible described the first ossification centre not far from $\mathrm{dm} 1$, in the position of the future mental foramen and other small centres inferior to the posterior ends of Meckel's cartilage [40]. Also, the development of Meckel's cartilage initiates in a similar area of the molar tooth bud region [41]. Another study of prenatal human mandibles identified a growth centre at the position of the first deciduous molar germ (dm1) [38] near the mental foramen, from which trabecular bone growth radiates outwardlargely, proximally, and distally_-across the corpus. A similar configuration was reported in human fetuses [74], where, again, ossification proceeds away from this centre in different directions [75]. Hypothetically, this growth centre might be a mechanism that allows or spurs corpus growth rates to vary on either side of it. Unfortunately, even if such growth centres and radial lines existed in the postnatal ape or baboon mandibles imaged here, then the higher exposure times and voltages necessary to properly capture the developing dental tissues all but obliterated the more delicate details of the trabeculae.

There are several detailed reports of specific local regulation of osteogenesis in the alveolus [76-78] and, more recently, the ramus [79]. For example, in the alveolus, parathyroid hormone-related protein (PTHrP) is critical to promote the osteoclast formation that maintains a bonefree area around each tooth [77]. In the periosteum of the ramus, various genes and their products including BMP2, osteocalcin, alkaline phosphotase, OPG/RANKL, and runx2 help to regionally modulate apposition (osteoblast activity) 


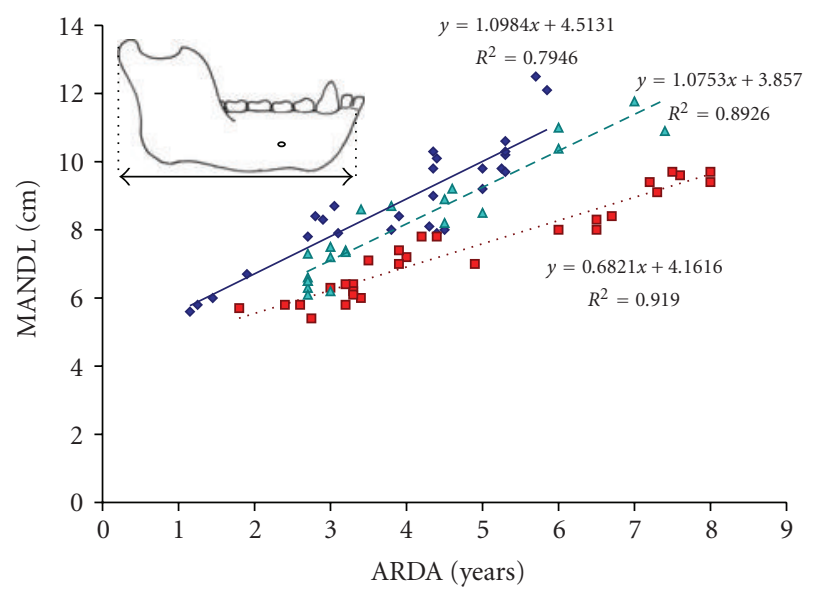

(a)

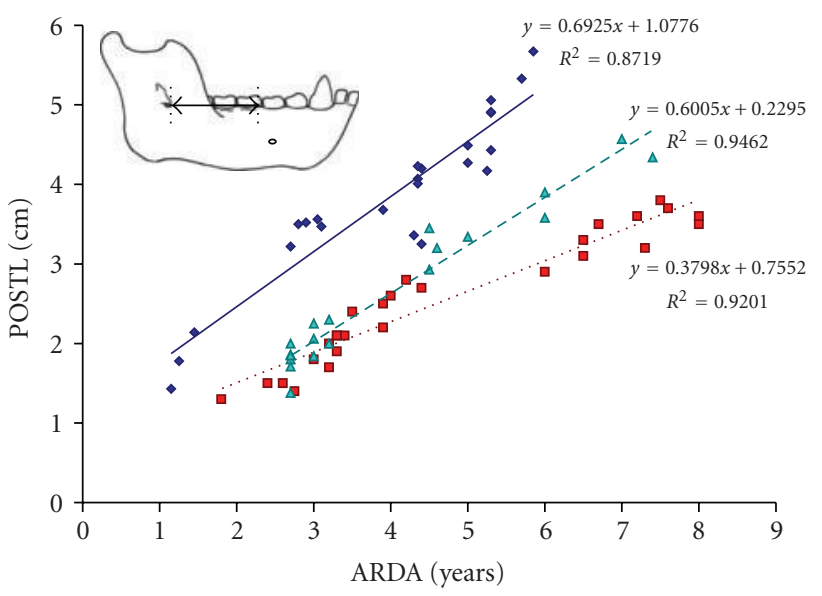

(b)

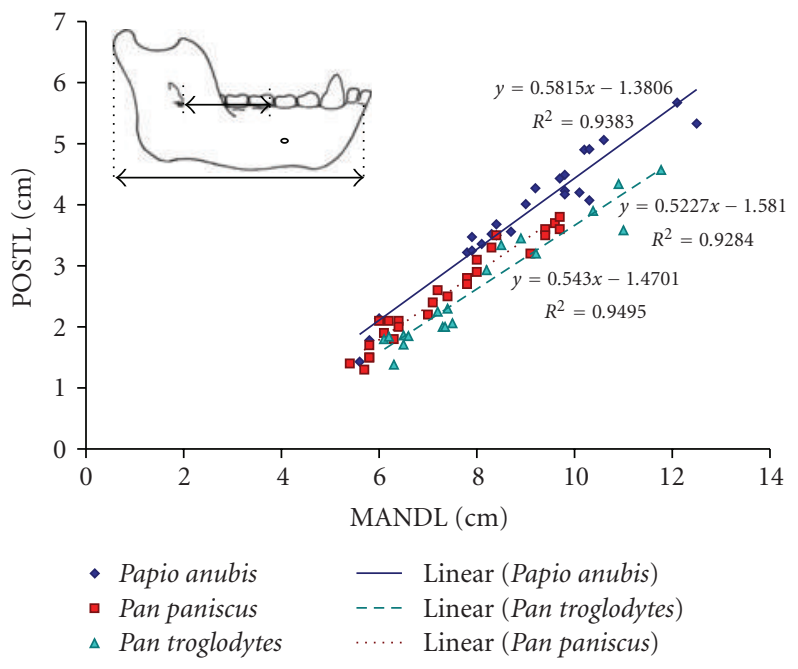

(c)

Figure 6: (a) Total mandible length (MANDL) grew at similar rates in Papio and Pan troglodytes, but more slowly and to shorter adult lengths in Pan paniscus. (b) Posterior corpus length (POSTL), where the permanent molars develop, grew to the longest adult lengths at the fastest rates in Papio. The inverse was seen in P. paniscus. (c) In all three species, POSTL grew to about half the length of MANDL. Red squares, Pan paniscus; teal triangles, Pan troglodytes; blue diamonds, Papio anubis.

and resorption (osteoclast activity) [79]. No published study of regional variation in dermal bone growth rate was found to help explain how growth rate might vary across the length of the mandible corpus. Regional variation in postnatal growth rates has been observed in long bones $[80,81]$ and may be related to localized mechanical stresses [82] and/or variation in growth factor (i.e., IGF-IR) expression in the growth plates [81]. Regional variation in corpus growth rate is not far fetched when one considers that there is regional variation in jawbone density based on loading [83]; both kinds of local change (biomechanical and developmental) in bone growth likely occur via similar osteogenic mechanisms. Variation in osteoblast and osteoclast activity across the jawbone may drive differences in corpus elongation rates in response to signalling or hormone gradients. Faster lengthening would be expected to correlate with higher numbers of proliferating osteocytes, among other factors.
The idea that one or more growth centres in the mandible facilitate different growth rates across the corpus has interesting implications for ontogenetic and evolutionary changes in jaw form in response to altered tooth proportion and/or number. Selection seems to act more strongly on the teeth than the mandible, where the face responds to change in the dentition rather than vice versa [17-19]. Segregated growth centres could facilitate faster and/or more precise local changes in mandible growth to accommodate specific odontological modifications while minimizing disruptions to adjacent, unimplicated regions of the jaw. While this is an interesting idea, much work needs to be done to test it.

\section{Conclusions}

Between Pan and Papio, mandible shape and ontogeny are statistically distinct. Thus, genus-level differences in 


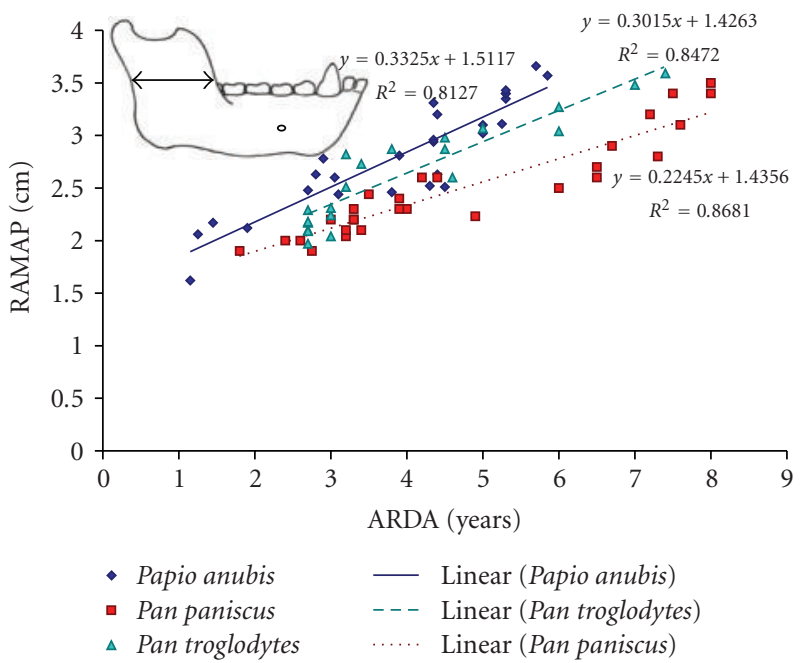

(a)

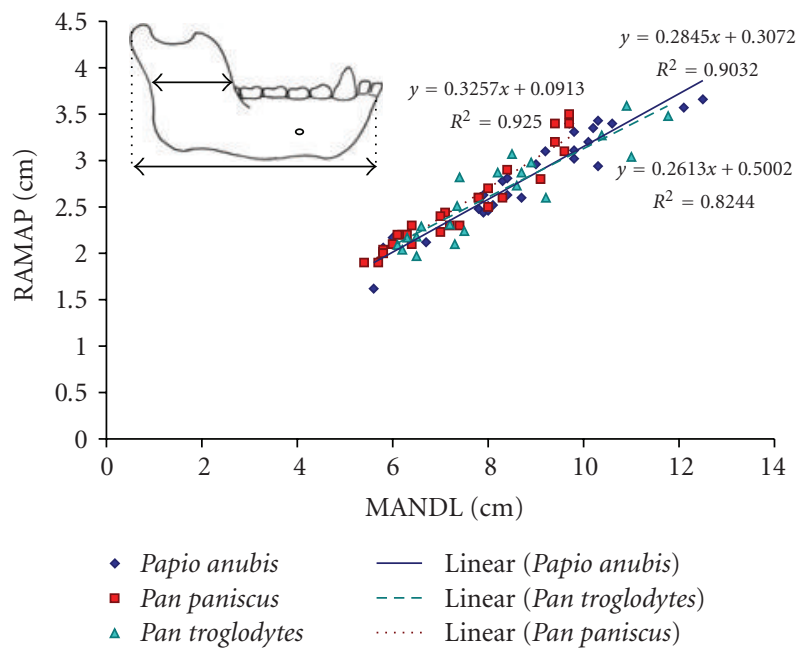

(b)

Figure 7: (a) Anteroposterior ramus width (RAMAP) increased fastest with age (ARDA) in Papio and Pan troglodytes, and more slowly in Pan paniscus. (b) RAMAP contributed to around one quarter of adult mandible length in Papio and P. troglodytes and closer to one-third in P. paniscus. Red squares, Pan paniscus; teal triangles, Pan troglodytes; blue diamonds, Papio anubis.

mandible morphology are not only present from birth but also arise and become entrenched via different postnatal growth trajectories. The mandible corpus lengthens at different rates between genera. Further, growth rate varies locally within the corpus. Regional variation in corpus growth rate and innate differences in corpus proportions appear to act in tandem to create space in a timely way for the permanent molars in Papio and Pan. Local growth rates across the corpus may evolve alongside changes in molar morphology and developmental timing to help the teeth and jaw remain ontogenetically and functionally compatible.

\section{Acknowledgments}

Thanks are due to Christopher Dean, Louise Humphrey, Paul O'Higgins, Sam Cobb, Wendy Dirks, Nick Jones, Don Reid, and Gary Schwartz for valuable discussions on the design of the study and statistical methods. Thanks are also due to the curators at the Natural History Museum, London, the Royal Museum of Central Africa, Tervuren, the PowellCotton Museum, Kent, and the Royal College of Surgeons, England. This research was funded in part by The Graduate School at University College London, and the University of Saskatchewan.

\section{References}

[1] S. W. Oka and B. S. Kraus, "The circumnatal status of molar crown maturation among the hominoidea," Archives of Oral Biology, vol. 14, no. 6, pp. 639-659, 1969.

[2] A. D. Beynon, M. C. Dean, and D. J. Reid, "Histological study on the chronology of the developing dentition in gorilla and orangutan," American Journal of Physical Anthropology, vol. 86, no. 2, pp. 189-203, 1991.
[3] L. A. Winkler, J. H. Schwartz, and D. R. Swindler, "Aspects of dental development in the orangutan prior to eruption of the permanent dentition," American Journal of Physical Anthropology, vol. 86, no. 2, pp. 255-271, 1991.

[4] R. L. Anemone, E. S. Watts, and D. R. Swindler, "Dental development of known-age chimpanzees, Pan troglodytes (primates, pongidae)," American Journal of Physical Anthropology, vol. 86, no. 2, pp. 229-241, 1991.

[5] L. A. Winkler, J. H. Schwartz, and D. R. Swindler, "Development of the orangutan permanent dentition: assessing patterns and variation in tooth development," American Journal of Physical Anthropology, vol. 99, no. 1, pp. 205-220, 1996.

[6] L. A. Winkler, "A comparison of radiographic and anatomical evidence of tooth development in infant apes," Folia Primatologica, vol. 65, no. 1, pp. 1-13, 1995.

[7] D. R. Swindler and A. D. Beynon, "The development and microstructure of the dentition of Theropithecus," in Theropithecus: The Rise and Fall of a Primate Genus, N. G. Jablonski, Ed., pp. 351-381, Cambridge University Press, Cambridge, UK, 1993.

[8] W. Dirks, "Histological reconstruction of dental development and age at death in a juvenile gibbon (Hylobates lar)," Journal of Human Evolution, vol. 35, no. 4-5, pp. 411-425, 1998.

[9] J. C. Boughner and M. C. Dean, "Does space in the jaw influence the timing of molar crown initiation? A model using baboons (Papio anubis) and great apes (Pan troglodytes, Pan paniscus)," Journal of Human Evolution, vol. 46, no. 3, pp. 255277, 2004.

[10] M. M. Smith and M. I. Coates, "Evolutionary origins of the vertebrate dentition: phylogenetic patterns and developmental evolution," European Journal of Oral Sciences, vol. 106, no. 1, pp. 482-500, 1998.

[11] G. J. Fraser, C. D. Hulsey, R. F. Bloomquist, K. Uyesugi, N. R. Manley, and J. T. Streelman, "An ancient gene network is coopted for teeth on old and new jaws," PLoS Biology, vol. 7, no. 2, Article ID e1000031, 2009. 
[12] A. Huysseune, J.-Y. Sire, and P. E. Witten, "Evolutionary and developmental origins of the vertebrate dentition," Journal of Anatomy, vol. 214, no. 4, pp. 465-476, 2009.

[13] M. M. Smith and M. I. Coates, "Evolutionary origins of teeth and jaws: developmental models and phylogenetic patterns," in Development, Function and Evolution of Teeth, M. F. Teaford, M. M. Smith, and M. W. J. Ferguson, Eds., pp. 133-151, Cambridge University Press, Cambridge, UK, 2000.

[14] Y. Shigetani, F. Sugahara, Y. Kawakami, Y. Murakami, S. Hirano, and S. Kuratani, "Heterotopic shift of epithelialmesenchymal interactions in vertebrate jaw evolution," Science, vol. 296, no. 5571, pp. 1316-1319, 2002.

[15] L. Humphrey, "Relative mandibular growth in humans, gorillas and chimpanzees," in Human Growth in the Past: Studies from Bones and Teeth, R. D. Hoppa and C. M. FitzGerald, Eds., pp. 65-87, Cambridge University Press, Cambridge, UK, 1999.

[16] C. T. James, A. Ohazama, A. S. Tucker, and P. T. Sharpe, "Tooth development is independent of a Hox patterning programme," Developmental Dynamics, vol. 225, no. 3, pp. 332-335, 2002.

[17] M. McCollum and P. T. Sharpe, "Evolution and development of teeth," Journal of Anatomy, vol. 199, no. 1-2, pp. 153-159, 2001.

[18] M. A. McCollum, "The robust australopithecine face: a morphogenetic perspective," Science, vol. 284, no. 5412, pp. 301-305, 1999.

[19] M. A. McCollum and P. T. Sharpe, "Developmental genetics and early hominid craniodental evolution," BioEssays, vol. 23, no. 6, pp. 481-493, 2001.

[20] D. J. Daegling, "Growth in the mandibles of African apes," Journal of Human Evolution, vol. 30, no. 4, pp. 315-341, 1996.

[21] A. B. Taylor and C. P. Groves, "Patterns of mandibular variation in Pan and Gorilla and implications for African ape taxonomy," Journal of Human Evolution, vol. 44, no. 5, pp. 529-561, 2003.

[22] M. L. Moss, "Functional cranial analysis of mammalian mandibular ramal morphology," Acta Anatomica, vol. 71, no. 3, pp. 423-447, 1968.

[23] M. L. Moss, "A functional analysis of human mandibular growth," The Journal of Prosthetic Dentistry, vol. 10, no. 6, pp. 1149-1159, 1960.

[24] H. Fukase and G. Suwa, "Influence of size and placement of developing teeth in determining anterior corpus height in prehistoric Jomon and modern Japanese mandibles," Anthropological Science, vol. 118, no. 2, pp. 75-86, 2010.

[25] W. Dirks, D. J. Reid, C. J. Jolly, J. E. Phillips-Conroy, and F. L. Brett, "Out of the mouths of baboons: stress, life history, and dental development in the Awash National Park hybrid zone, Ethiopia," American Journal of Physical Anthropology, vol. 118, no. 3, pp. 239-252, 2002.

[26] D. J. Reid, G. T. Schwartz, C. Dean, and M. S. Chandrasekera, "A histological reconstruction of dental development in the common chimpanzee, Pan troglodytes," Journal of Human Evolution, vol. 35, no. 4-5, pp. 427-448, 1998.

[27] P. D Jenkins, Catalogue of Primates in the British Museum (Natural History) Part V: The Apes, Superfamily Hominoidea, Natural History Museum, London, UK, 1990.

[28] P. H. Napier, Catalogue of Primates in the British Museum (Natural History) Part II: Family Cercopithecoidea, Subfamily Cercopithecinae, Natural History Museum, London, UK, 1981.

[29] J. C. Boughner, Dental and Mandibular Growth in Papio and Pan, Ph.D. thesis, University College London (University of London), London, UK, 2002.
[30] F. L. Bookstein, Morphometric Tools for Landmark Data: Geometry and Biology, Cambridge University Press, Cambridge, UK, 1991.

[31] I. L. Dryden and K. V. Mardia, Statistical Shape Analysis, John Wiley \& Sons, London, UK, 1st edition, 1998.

[32] L. F. Marcus, M. Corti, A. Loy, G. J. P. Naylor, and D. E. Slice, Advances in Morphometrics, Plenum Press, New York, NY, USA, 1996.

[33] P. O'Higgins and N. Jones, "Facial growth in Cercocebus torquatus: an application of three-dimensional geometric morphometric techniques to the study of morphological variation," Journal of Anatomy, vol. 193, part 2, pp. 251-272, 1998.

[34] D. Slice, GRF-ND Generalized Rotational Fitting of $N$ Dimensional Landmark Data, Department of Ecology and Evolution, State University of New York, Stony Brook, NY, USA, 1993.

[35] F. J. Rohlf and D. Slice, "Extensions of the Procrustes method for the optimal superimposition of landmarks," Systematic Zoology, vol. 39, no. 1, pp. 40-59, 1990.

[36] C. R. Goodall, "Procrustes methods in the statistical analysis of shape," Journal of the Royal Statistical Society, vol. 53, no. 2, pp. 285-339, 1991.

[37] M. Collard and P. O'Higgins, "Ontogeny and homoplasy in the papionin monkey face," Evolution and Development, vol. 3, no. 5, pp. 322-331, 2001.

[38] S. K. Lee, Y. S. Kim, H. S. Oh, K. H. Yang, E. C. Kim, and J. G. Chi, "Prenatal development of the human mandible," Anatomical Record, vol. 263, no. 3, pp. 314-325, 2001.

[39] Y. P. Liu, R. G. Behrents, and P. H. Buschang, "Mandibular growth, remodeling, and maturation during infancy and early childhood," Angle Orthodontist, vol. 80, no. 1, pp. 97-105, 2010.

[40] R. J. Radlanski, H. Renz, and M. C. Klarkowski, "Prenatal development of the human mandible. $3 \mathrm{D}$ reconstructions, morphometry and bone remodelling pattern, sizes 12117 mm CRL," Anatomy and Embryology, vol. 207, no. 3, pp. 221-232, 2003.

[41] G. E. Wise and G. J. King, "Mechanisms of tooth eruption and orthodontic tooth movement," Journal of Dental Research, vol. 87, no. 5, pp. 414-434, 2008.

[42] S. Hartwig-Scherer and R. D. Martin, "Allometry and prediction in hominoids: a solution to the problem of intervening variables," American Journal of Physical Anthropology, vol. 88, no. 1, pp. 37-57, 1992.

[43] J. C. Boughner and M. C. Dean, "Mandibular shape, ontogeny and dental development in bonobos (Pan paniscus) and Chimpanzees (Pan troglodytes)," Evolutionary Biology, vol. 35, no. 4, pp. 296-308, 2008.

[44] B. H. Smith, T. L. Crummett, and K. L. Brandt, "Ages of eruption of primate teeth: a compendium for aging individuals and comparing life histories," American Journal of Physical Anthropology, vol. 37, supplement 19, pp. 177-231, 1994.

[45] D. R. Swindler and D. Meekins, "Dental development of the permanent mandibular teeth in the baboon, Papio cynocephalus," American Journal of Human Biology, vol. 3, no. 6, pp. 571-580, 1991.

[46] V. S. Aggarwal, C. Carpenter, L. Freyer, J. Liao, M. Petti, and B. E. Morrow, "Mesodermal Tbx1 is required for patterning the proximal mandible in mice," Developmental Biology, vol. 344, no. 2, pp. 669-681, 2010. 
[47] M. Mina, Y. H. Wang, A. M. Ivanisevic, W. B. Upholt, and B. Rodgers, "Region- and stage-specific effects of FGFs and BMPs in chick mandibular morphogenesis," Developmental Dynamics, vol. 223, no. 3, pp. 333-352, 2002.

[48] S. Creuzet, G. Couly, C. Vincent, and N. M. Le Douarin, "Negative effect of Hox gene expression on the development of the neural crest-derived facial skeleton," Development, vol. 129, no. 18, pp. 4301-4313, 2002.

[49] A. Trumpp, M. J. Depew, J. L. R. Rubenstein, J. M. Bishop, and G. R. Martin, "Cre-mediated gene inactivation demonstrates that FGF8 is required for cell survival and patterning of the first branchial arch," Genes and Development, vol. 13, no. 23, pp. 3136-3148, 1999.

[50] A. S. Tucker, G. Yamada, M. Grigoriou, V. Pachnis, and P. T. Sharpe, "Fgf-8 determines rostral-caudal polarity in the first branchial arch," Development, vol. 126, no. 1, pp. 51-61, 1999.

[51] W. R. Atchley and B. K. Hall, "A model for development and evolution of complex morphological structures," Biological Reviews of the Cambridge Philosophical Society, vol. 66, no. 2, pp. 101-157, 1991.

[52] J. Kieser, "Biomechanics of masticatory force production," Journal of Human Evolution, vol. 36, no. 5, pp. 575-579, 1999.

[53] W. L. Hylander, "Mandibular function and biomechanical stress and scaling," American Zoologist, vol. 25, no. 2, pp. 315330, 1985.

[54] M. A. Spencer and B. Demes, "Biomechanical analysis of masticatory system configuration in neandertals and inuits," American Journal of Physical Anthropology, vol. 91, no. 1, pp. 1-20, 1993.

[55] T. G. Boyd, W. A. Castelli, and D. F. Huelke, "Removal of the temporalis muscle from its origin: effects on the size and shape of the coronoid process," Journal of Dental Research, vol. 46, no. 5, pp. 997-1001, 1967.

[56] S. L. Horowitz and H. H. Shapiro, "Modification of skull and jaw architecture following removal of the masseter muscle in the rat," American Journal of Physical Anthropology, vol. 13, no. 2, pp. 301-308, 1955.

[57] N. Hunt, "Muscle function and the control of facial form," in Clinical Oral Science, M. Harris, M. Edgar, and S Meghji, Eds., pp. 120-133, Wright, Oxford, UK, 1998.

[58] S. Kiliaridis, C. Mejersjö, and B. Thilander, "Muscle function and craniofacial morphology: a clinical study in patients with myotonic dystrophy," European Journal of Orthodontics, vol. 11, no. 2, pp. 131-138, 1989.

[59] S. K. Nanda, W. W. Merow, and V. Sassouni, "Repositioning of the masseter muscle and its effect on skeletal form and structure," Angle Orthodontist, vol. 37, no. 4, pp. 304-308, 1967.

[60] A. B. Taylor, "Masticatory form and function in the African apes," American Journal of Physical Anthropology, vol. 117, no. 2, pp. 133-156, 2002.

[61] S. C. Antón, "Cranial adaptation to a high attrition diet in Japanese macaques," International Journal of Primatology, vol. 17, no. 3, pp. 401-427, 1996.

[62] E. L. du Brul, "Early hominid feeding mechanisms," American Journal of Physical Anthropology, vol. 47, no. 2, pp. 305-320, 1977.

[63] J. W. Osborn, "Relationship between the mandibular condyle and the occlusal plane during hominid evolution: some of its effects on jaw mechanics," American Journal of Physical Anthropology, vol. 73, no. 2, pp. 193-207, 1987.

[64] G. S. Throckmorton, R. A. Finn, and W. H. Bell, "Biomechanics of differences in lower facial height," American Journal of Orthodontics, vol. 77, no. 4, pp. 410-420, 1980.
[65] S. C. Antón, "Macaque masseter muscle: internal architecture, fiber length and cross-sectional area," International Journal of Primatology, vol. 20, no. 3, pp. 441-462, 1999.

[66] R. K. Malenky and R. W. Wrangham, "A quantitative comparison of terrestrial herbaceous food consumption by Pan paniscus in the Lomako Forest, Zaire, and Pan troglodytes in the Kibale Forest, Uganda," American Journal of Primatology, vol. 32, no. 1, pp. 1-12, 1994.

[67] R. K. Malenky, S. Kuroda, E. O. Vineberg, and R. W. Wrangham, "The significance of terrestrial herbaceous foods for bonobos, chimpanzees and gorillas," in Chimpanzee Cultures, R. W. Wrangham, W. C. McGrew, F. B. M deWaal, and P. G. Heltne, Eds., pp. 59-75, Chicago Academy of Sciences, Chicago, Ill, USA, 1994.

[68] R. W. Wrangham, C. A. Chapman, and L. J. Chapman, "Seed dispersal by forest chimpanzees in Uganda," Journal of Tropical Ecology, vol. 10, no. 3, pp. 355-368, 1994.

[69] M. A. McCollum, "Rethinking incisor size and diet in anthropoids: diet, incisor wear and incisor breadth in the African apes," American Journal of Physical Anthropology, vol. 133, no. 3, pp. 986-993, 2007.

[70] M. A. McCollum and W. C McGrew, "Dental evolution in the genus Pan," American Journal of Physical Anthropology, vol. 114, p. 105, 2001.

[71] I. DeVore and S. L. Washburn, "Baboon ecology and human evolution," in African Ecology and Human Evolution, F. Clark Howell and F. Bourliere, Eds., Viking Fund Publications in Anthropology no. 36, pp. 335-367, Wenner-Gren Foundation for Anthropological Research, London, UK, 1963.

[72] S. L. Washburn and I. DeVore, "Social behavior of baboons and early man," in Social Life of Early Man, S. L. Washburn, Ed., Viking Fund Publications in Anthropology no. 31, pp. 91105, Aldine Publishing Company, Chicago, Ill, USA, 1961.

[73] T. E. Rowell, "Forest living baboons in Uganda," Journal of Zoology, vol. 149, no. 3, pp. 344-364, 1966.

[74] T. Orliaguet, P. Dechelotte, T. Scheye, and G. Vanneuville, "Relations between Meckel's cartilage and the morphogenesis of the mandible in the human embryo," Surgical and Radiologic Anatomy, vol. 15, no. 1, pp. 41-46, 1993.

[75] J. M. Smartt Jr., D. W. Low, and S. P. Bartlett, "The pediatric mandible: I. A primer on growth and development," Plastic and Reconstructive Surgery, vol. 116, no. 1, pp. 14e-23e, 2005.

[76] Y. Kitahara, N. Suda, T. Kuroda, F. Beck, V. E. Hammond, and Y. Takano, "Disturbed tooth development in parathyroid hormone-related protein (PTHrP)-gene knockout mice," Bone, vol. 30, no. 1, pp. 48-56, 2002.

[77] Y. Kitahara, N. Suda, T. Terashima et al., "Accelerated bone formation and increased osteoblast number contribute to the abnormal tooth germ development in parathyroid hormonerelated protein knockout mice," Bone, vol. 35, no. 5, pp. 11001106, 2004.

[78] K. Mekaapiruk, N. Suda, V. E. Hammond et al., "The influence of parathyroid hormone-related protein (PTHrP) on toothgerm development and osteoclastogenesis in alveolar bone of PTHrP-knock out and wild-type mice in vitro," Archives of Oral Biology, vol. 47, no. 9, pp. 665-672, 2002.

[79] Z. Sun and B. C. Tee, "Molecular variations related to the regional differences in periosteal growth at the mandibular ramus," Anatomical Record, vol. 294, no. 1, pp. 79-87, 2011.

[80] A. L. Lerner and J. L. Kuhn, "Characterization of regional and age-related variations in the growth of the rabbit distal femur," Journal of Orthopaedic Research, vol. 15, no. 3, pp. 353-361, 1997. 
[81] M. A. Serrat, C. O. Lovejoy, and D. King, "Age- and site-specific decline in insulin-like growth factor-I receptor expression is correlated with differential growth plate activity in the mouse hindlimb," Anatomical Record, vol. 290, no. 4, pp. 375-381, 2007.

[82] A. L. Lerner, J. L. Kuhn, and S. J. Hollister, "Are regional variations in bone growth related to mechanical stress and strain parameters?" Journal of Biomechanics, vol. 31, no. 4, pp. 327335, 1998.

[83] Q. Wang, D. W. Ashley, and P. C. Dechow, "Regional, ontogenetic, and sex-related variations in elastic properties of cortical bone in baboon mandibles," American Journal of Physical Anthropology, vol. 141, no. 4, pp. 526-549, 2010. 

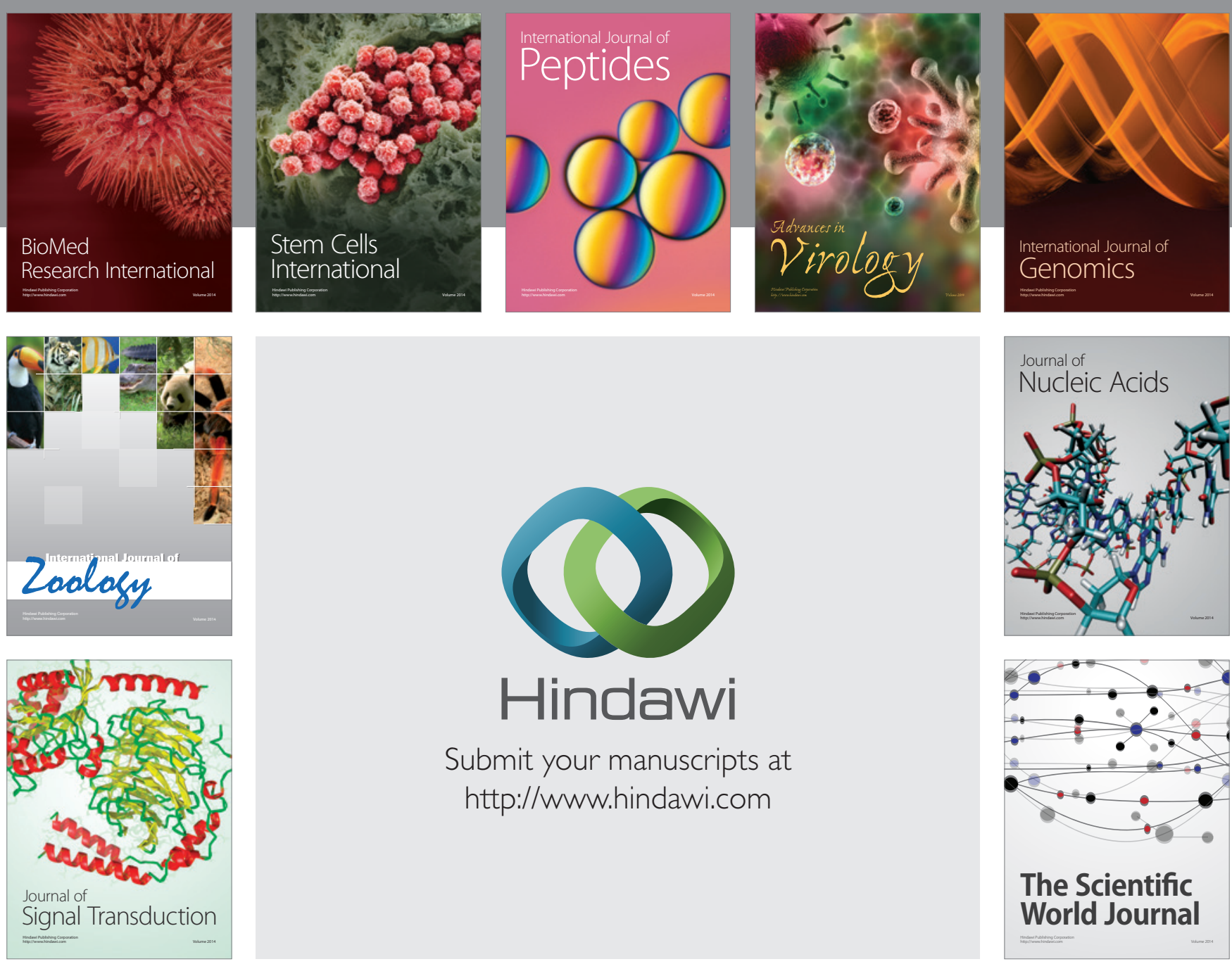

Submit your manuscripts at

http://www.hindawi.com
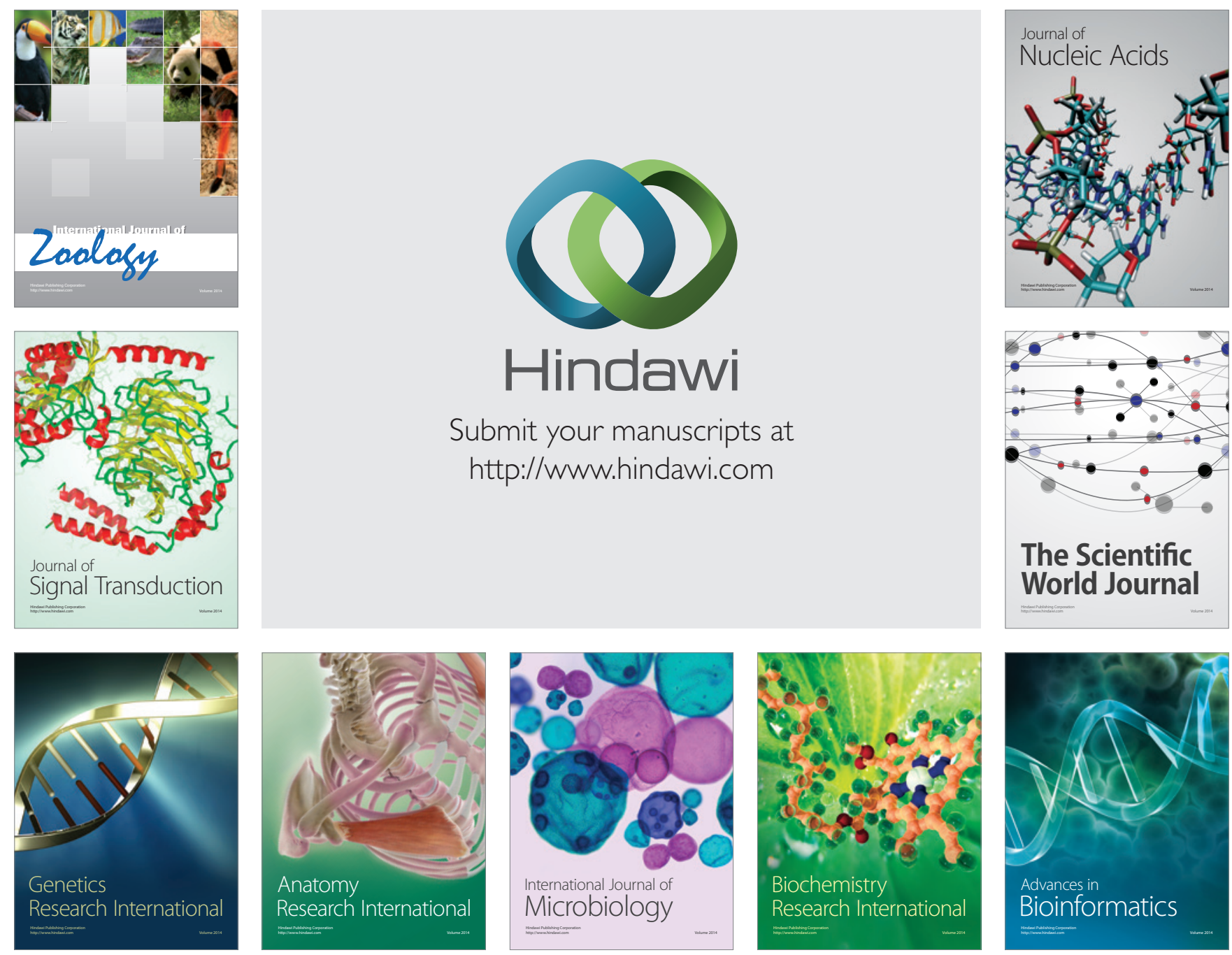

The Scientific World Journal
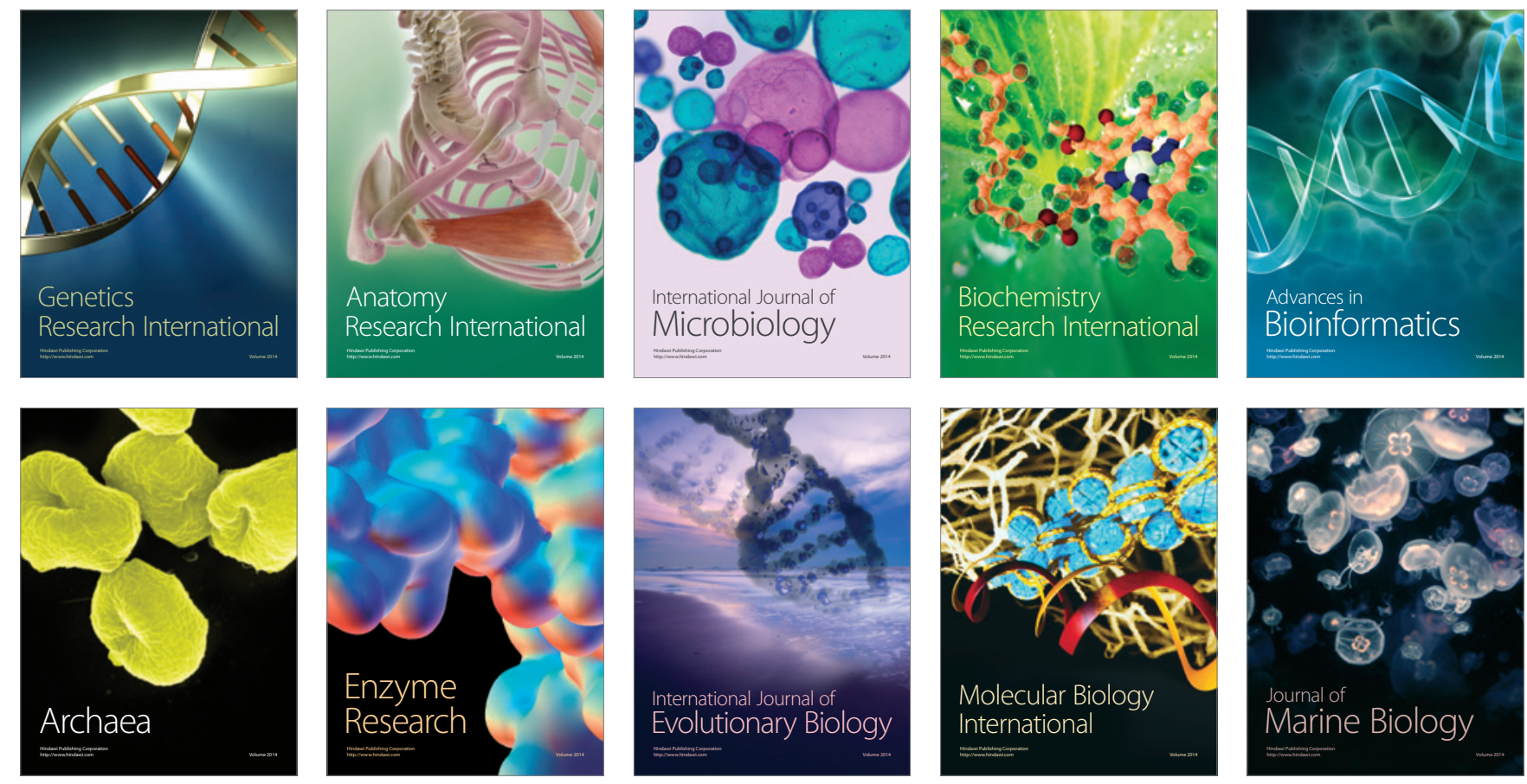